\title{
Modeling the effects of future urban planning scenarios on the Urban Heat Island in a complex region
}

\author{
Sylvain Labedens ${ }^{1,2}$, Jean-Louis Scartezzini ${ }^{2}$, Dasaraden Mauree ${ }^{2}$ \\ 1 Université de Pau et des Pays de l'Adour, Institut Supérieur Aquitain du BTP, 64600 Anglet, France, \\ s.labedens@gmail.com 2 Solar Energy and Building Physics Laboratory. Ecole Polytechnique Fé dé rale de Lausanne, \\ CH-1015 Lausanne, Switzerland, dasaraden.mauree@epfl.ch
}

\section{ABSTRACT}

Because of the global warming, urban planning strategies must be investigated to reduce the building energy consumption and increase the thermal comfort in cities. In the framework of Energy Strategy 2050 of Switzerland, this research aim to highlight the impact of future climate change on urban planning and proposes strategies to help urban planners and policymakers face this new challenge particularly in a future where heat waves are going to become common at mid-latitudes. However, to do so in the best possible way, the models currently used have to be robust enough in complex regions (with lakes and mountains) to evaluate future planning scenarios. First, this study proposes a methodology to cluster buildings in urban areas and use it in a mesoscale numerical weather prediction system to evaluate the urban heat island and its impact on the energy demand for cooling at the city scale. Second, this research proposes urban planning strategies to reduce building energy consumption due to the urban heat island phenomenon in the city of Lausanne.

The model has been validated with six different weather stations. It emphasizes the presence of the urban heat island in the Lemanic region which lead to the increase of air temperatures in Geneva and Lausanne by $2^{\circ} \mathrm{C}$ during the day and by up $4^{\circ} \mathrm{C}$ during the night compared to the surrounding areas. The presence of multiple cities around the lake lead to the creation of the urban heat archipelago. We demonstrate with these simulations that the performance of the 
This is a pre-print of manuscript submitted for peer-review at Urban Climate

WRF model is very heterogeneous in this complex setting. In the evaluation of the future urban densification scenario, we noted that there will be an increase in temperature caused by the UHI phenomenon by up $0.6^{\circ} \mathrm{C}$. The increase of albedo of roofs and walls and the use of greenings are good mitigation solutions, with a most significant impact for the albedo. In addition to the climatic impact, the model highlights that the densification scenario has a significant impact on the peak cooling demand.

\section{KEYWORDS}

Urban Heat Island; UHI mitigation strategies; Urban planning; Weather Research and Forecasting model simulation

\section{INTRODUCTION}

By 2050, two persons out of three will probably live in cities or urban areas (United Nations, 2017). It is expected that climate change will increase the frequency of heat waves and hence put urban dwellers at risk (IPCC, 2013). Additionally, the presence of human activities in urban zones and the modification of the land surface, affects the climate in urban areas. Moreover, the new Swiss territorial planning law's revision (LAT) voted in 2014 (ARE) along with the Swiss Energy strategy 2050 framework promotes the urban densification development. With the global warming, extended heatwaves, such as those of 2003 and 2018, will become more common and the impact of the future land use on the urban climate is still unknown in these extreme conditions.

One of the main consequences of built-up areas is the elevation of temperatures as compared to the rural surrounding, also called the Urban Heat Island (UHI) (Arnfield, 2003; Oke, 1982). UHI 
This is a pre-print of manuscript submitted for peer-review at Urban Climate

intensity can be defined as the difference between the temperatures in the cities and in the rural area. It is specific to a given local meteorology, the anthropogenic heat and other urban properties such as the size, the morphology, the impervious surfaces and the building materials characteristics (Nunez and Oke, 1977). The impact of UHI on the global warming is still poorly understood (Alcoforado and Andrade, 2008) but its influence on the urban climate has been proved (Santamouris et al., 2001a). Several studies have demonstrated its influence on the urban pollution (Fallmann et al., 2014; Xu et al., 2018), the pedestrian comfort (Mauree et al., 2016) and the building energy consumption (Coccolo et al., 2018; Mauree et al., 2017b; Santamouris, 2013). To minimize these effects, UHI mitigation strategies have been investigated. The use of trees (Akbari et al., 2001; Krayenhoff and Voogt, 2007) and greening surfaces (Coccolo et al., 2018) improve the urban comfort and the air quality. Moreover, by increasing the albedo using reflective materials in urban areas, the heat storage and buildings energy consumption can be reduced (Morini et al., 2016; Touchaei and Akbari, 2015). To model these UHI mitigation strategies and to increase the understanding of the phenomenon, different urban climate models have been developed.

At the meso-scale, different ways have been explored to model the urban climate. Liu et al (2006) and Sakar and De Ridder (2011) propose to modify the thermal roughness length to represent urban zones. The modification of the thermal conductivity and heat capacity compared to the natural soil's properties can assess the influence of the roughness length, albedo, building materials characteristics and vegetation on the city heat storage. Nevertheless, this simple urban surface parameterization cannot represent the urban heterogeneities and the impact of the urban morphology on the UHI. In order to have a better representation of horizontal and vertical surfaces, single and multi-layer urban canopy models have been integrated in atmospheric models. The single-layer urban canopy models represent the cities by infinite long streets canyons 
This is a pre-print of manuscript submitted for peer-review at Urban Climate

and three different surfaces (roofs, roads and walls) (Masson 2000; Kusaka et al. 2001; Kanda et al. 2005). This inclusion of 3D geometries thus allows to take the urban morphology into account in the calculation. Therefore, these single layer models enable the computation of various parameters such as the energy budget of roofs, roads and walls, the assessment of the shadowing, the reflection, the trapping of radiation and the wind speed above the canyons as well as the simulation of the heat urban island's magnitude (Trusilova et al., 2013). However, they interpolate the results only at the lowest point of the atmospheric layer, which does not allow for studies of vertical heat fluxes profiles. Thus, multi-layer urban canopy models have been developed to model urban air pollution (Clappier et al. 1996; Martilli et al. 2002) and the building energy consumption (Kondo et al., 2005). The Building Effects Parametrization (BEP) (Martilli et al. 2002) together with a mesoscale numerical weather prediction system, like the Weather Research and Forecasting (WRF) model (Skamarock 2008; Chen et al. 2011), compute the interaction between buildings and the planetary boundary layer. BEP recognizes 3D geometries and takes into account the vertical distribution of buildings heat fluxes, the effect of the geometry on the momentum and the turbulent kinetic energy, the building materials characteristics on the energy budget and the shadowing as well as the reflections and trapping of short and long wave radiation in urban canyons. To simulate the interaction between buildings' interiors and exteriors (Kikegawa et al., 2003), Salamanca et al. (2010) developed the Building Energy Model (BEM). This model can compute the building energy demand due to the heating, cooling and ventilation demands, the diffusion of heat through the roofs, walls and floors as well as the longwave radiation exchanged between indoor surfaces. With the coupling BEP+BEM integrated in WRF, it is possible to assess the impact of anthropogenic heat on the atmosphere and, more precisely, the vicious circle of the air conditioning (Salamanca et al., 2010). 
This is a pre-print of manuscript submitted for peer-review at Urban Climate

At the micro-scale, a software like ENVI-met (Bruse and Fleer, 1998), CitySIM (Robinson, 2012) or EnergyPus (Crawley et al., 2000) can compute the impact of the buildings activity on the urban climate and the latter on the building energy consumption more accurately than meso-scale models. However, these models work only at the street or neighborhood scale. To study the energy flux exchanges between the city and the atmosphere, meteorological models with high resolution should be used. They are however computationally very expensive and not feasible (Martilli, 2007). It can thus be advantageous to obtain high-resolution boundary condition for the micro-scale models from the meso-scale models. The Canopy Interface Model (CIM) (Mauree, 2014; Mauree et al., 2017a) has recently been coupled with WRF (Mauree et al., 2018) and in an offline mode with the CitySim model to create a multi-scale meteorological system. CIM resolves for vertical profiles of meteorological variables from low-resolution models and provides meteorological boundary conditions for micro-scale models which improve the assessment quality of building energy demand (Mauree et al., 2015b, 2015a, 2017b).

Although both meso and micro-scale models have been used extensively in the recent years, it is still not clear how future land uses are going to impact the urban climate and how this will translate in terms of energy consumption at the local and city scale. It is particularly difficult to estimate the impact when land use inputs are difficult to obtain, specifically for the urban area. This is also the case at the national scale of Switzerland where no classification exists. Therefore, the first purpose of this paper is to propose a strategy to define the national urban land use in order to elaborate inputs for WRF. The second is to model the impact of the urban densification strategy on the $\mathrm{UHI}$ and the building energy demand during heatwaves. Finally, we propose some strategies to mitigate the urban densification's effects by changing the albedo and the green fractions. 
This is a pre-print of manuscript submitted for peer-review at Urban Climate

The paper is structured as follows: in section 2 we give the methodology used to cluster the urban area and to simulate the urban climate and in section 3 we detail the case study and the experiments that will be conducted. Section 4 present the results of the meteorological and energetic simulations and finally in section 5 we give our conclusion about the impact of the future densification on the urban climate and its impact on the cooling demand.

\section{Methodology}

\subsection{WRF}

WRF is an atmospheric model developed by the National Center for Atmospheric Research (NCAR). It is a set of several programs used for both research and numerical weather prediction (NWP). In our case, the model enables to simulate the urban climate from urban land covers.

The WRF execution program WRF.exe is preceded by a set of three programs from the WRF Preprocessing System (WPS), which collect and prepare input for the real program (Fig. 1). The WPS is made up of the GEOGRID, which uses terrestrial data collected from remote sensing data such as MODIS (Channan et al., 2014) to define the simulation domain; the UNGRIB, that extracts meteorological data via GRIB file links and the METGRID, which horizontally interpolates the meteorological data into the simulation domain. The real.exe vertically interpolates the METGRID output data and prepares WRF inputs for the meteorological model WRF.exe. 
This is a pre-print of manuscript submitted for peer-review at Urban Climate

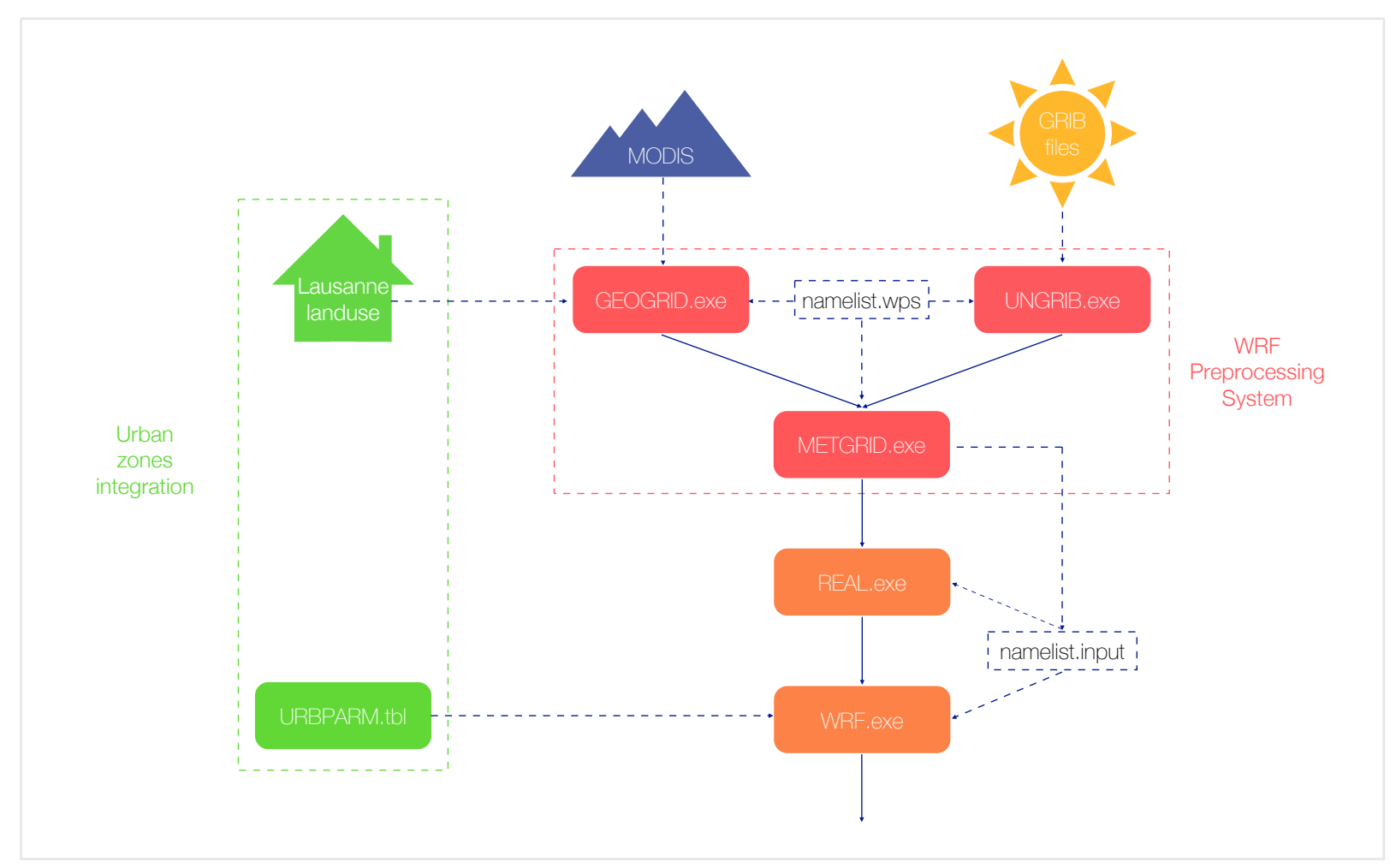

Fig. 1. Flowchart of the WPS process

More information about urban characteristics can be integrated in WRF via the URBPARM.tbl and using the GEOGRID.exe. The first one collects urban characteristics (see Appendix A) and the second one can use urban land use during the simulation domain definition process (integration detailed in section 2.2.3).

\subsection{LANDUSE}

\subsubsection{CLUSTERING}

WRF uses the MODIS land cover classification developed by the University of Maryland and the NASA to define the land cover of the studied domain. But the MODIS classification initially takes into account only one urban class. To complete the existing MODIS and to obtain a good representation of Swiss urban area, we have defined the three standard urban classes previously 
This is a pre-print of manuscript submitted for peer-review at Urban Climate

described by Chen et al., (2011) : the low-density residential (class 31), the high-density residential (class 32) and the industrial and commercial (class 33). Based on the classification proposed by Stewart et al., (2012), these classes correspond to the LCZ 2, 3 and 8 respectively.

To distribute the urban area in these three urban landuse categories of MODIS, the Swiss land cover has been divided in pixels of $200 \mathrm{~m} \times 200 \mathrm{~m}$ size (Assouline et al., 2018). Each of these pixels contains data extracted from the national database RegBL such as: the number of buildings, the building footprint, the building heights, the construction year, the building use, the fuel and the type of heating and cooling system. To take into account the spatial variability of the landuse, the pixels of urban area are clustered by the building footprint data with the $k$-means clustering method (MacQueen, 1967). The $k$-means method is a clustering method enables to automatically partition a data set into $k$ groups, here into the three urban categories of MODIS. We have chosen this algorithm because the method enables to manage a massive database with a reasonably low processing time and it is easily reproducible for any urban area. In our case, the algorithm dispatch the urban area in the three urban land uses used in WRF to obtain a significant urban morphology for the whole country.

To integrate this new urban landscape in WRF and to work at the optimum high-resolution of WRF, the clusters of $200 \mathrm{~m}$ size are resampled in a resolution of $1 \mathrm{~km}$ by the nearest neighbor method. The latter is the most suitable method to resample nominal data, such as the three urban categories described previously. The resampling process and the mapping are done with the geospatial processing program ArcMap suite of ArcGIS. 
This is a pre-print of manuscript submitted for peer-review at Urban Climate

From this raster, two WRF input text files are created: the URBFRAC.txt which contains the urban fraction of each country zones, and the LANDUSE.txt which contains the urban category of each urban zones. This process is detailed in the Fig. 2 .

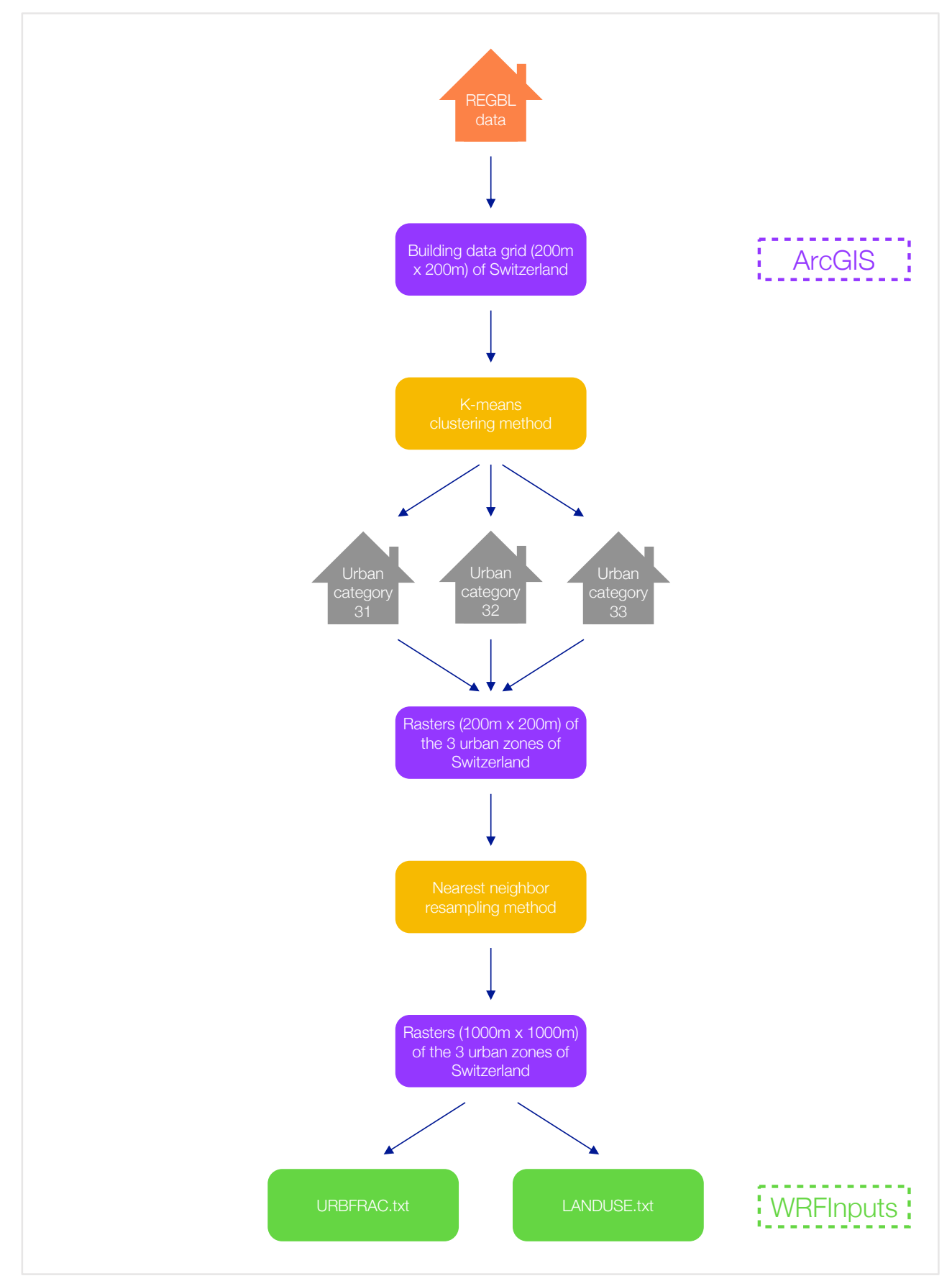

Fig. 2. Flowchart of the clustering process of the Swiss urban zones 
This is a pre-print of manuscript submitted for peer-review at Urban Climate

\subsubsection{INTEGRATION OF URBAN ZONES IN WRF}

To integrate urban zones in this process, we have collected the urban fraction of each urban zones in the URBFRAC text file, converted in binary file thereafter (Fig. 3). The INDEX file collects urban fraction data for the urban zones and uses the MODIS data for the non-urban zones. Then, the three urban categories from the MODIS landuse categories are added in the GEOGRID by the LANDUSE.tbl. Finally, the characteristics of each urban categories (building heights and widths, building materials characteristics, albedo of roofs and walls, greenings ratio...) are defined in the URBPARM.tbl file and used during the wrf.exe processing (Fig. 1).

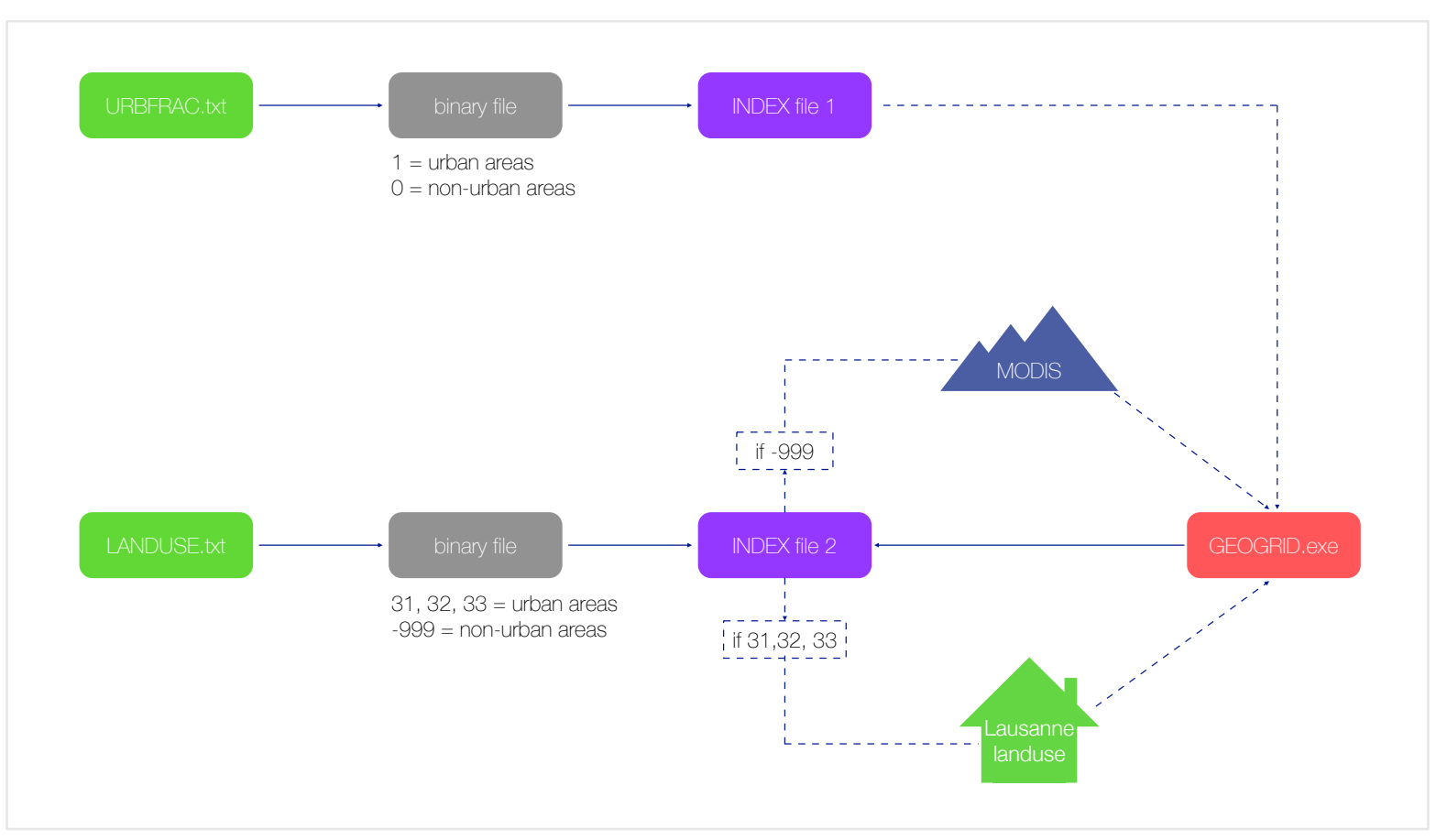

Fig. 3. Flowchart of the integration process of urban characteristics in the WPS

To model more precisely the urban morphology of Lausanne, we have also taken into account the streets directions by plotting the polar histogram distribution of street orientations with the OSMnx Python package (Boeing, 2017) (Fig. 4). 


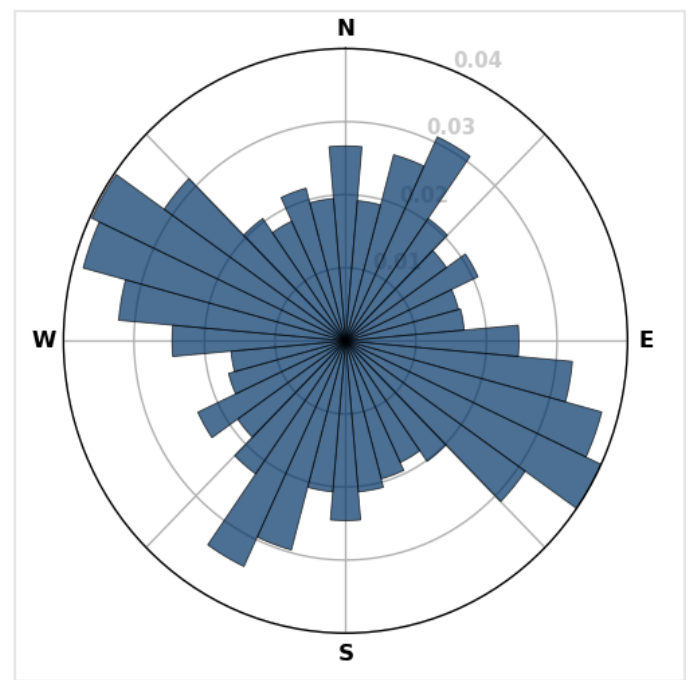

Fig. 4. Distribution of the street orientations of Lausanne

To model the urban materials' characteristics of Lausanne, the heat capacity as well as the thermal conductivity of the buildings and roads materials of Neuchâtel, Switzerland (Perez 2014) have been used. For each period of construction, typical heat capacity and thermal conductivity have been collected. The final value is the typical heat capacity and thermal conductivity rated by the number of buildings' percentage for each construction period. The urban parametrization of each urban classes in Appendix A.

\subsection{CIM / CITYSIM}

CIM-CitySim models are used to assess the building energy demand of an urban area of a neighborhood in of Lausanne. The Canopy Interface Model (CIM) is a 1D-column model. It collects meteorological data from WRF or Meteonorm and calculates vertical profile of wind speed and air temperature. CitySim is an urban energy modelling tool based on an analogy with electrical circuit. It can quantify the building energy demand at the city scale.

The coupling strategy, previously developed by Mauree et al., (2017c) is illustrated in Fig. 5. At the initialization, CitySim provides buildings geometry (height and width) to CIM. For every time 
This is a pre-print of manuscript submitted for peer-review at Urban Climate

step, CitySim calculates the surface temperatures from meteorological data of WRF outputs. Then, CIM uses the surface temperatures and the building geometry from CitySim and horizontal wind speed, wind direction and air temperature from WRF outputs to calculate local urban meteorological data. Finally, these data are used as boundary conditions by CitySim to quantify the energy demand of the buildings.

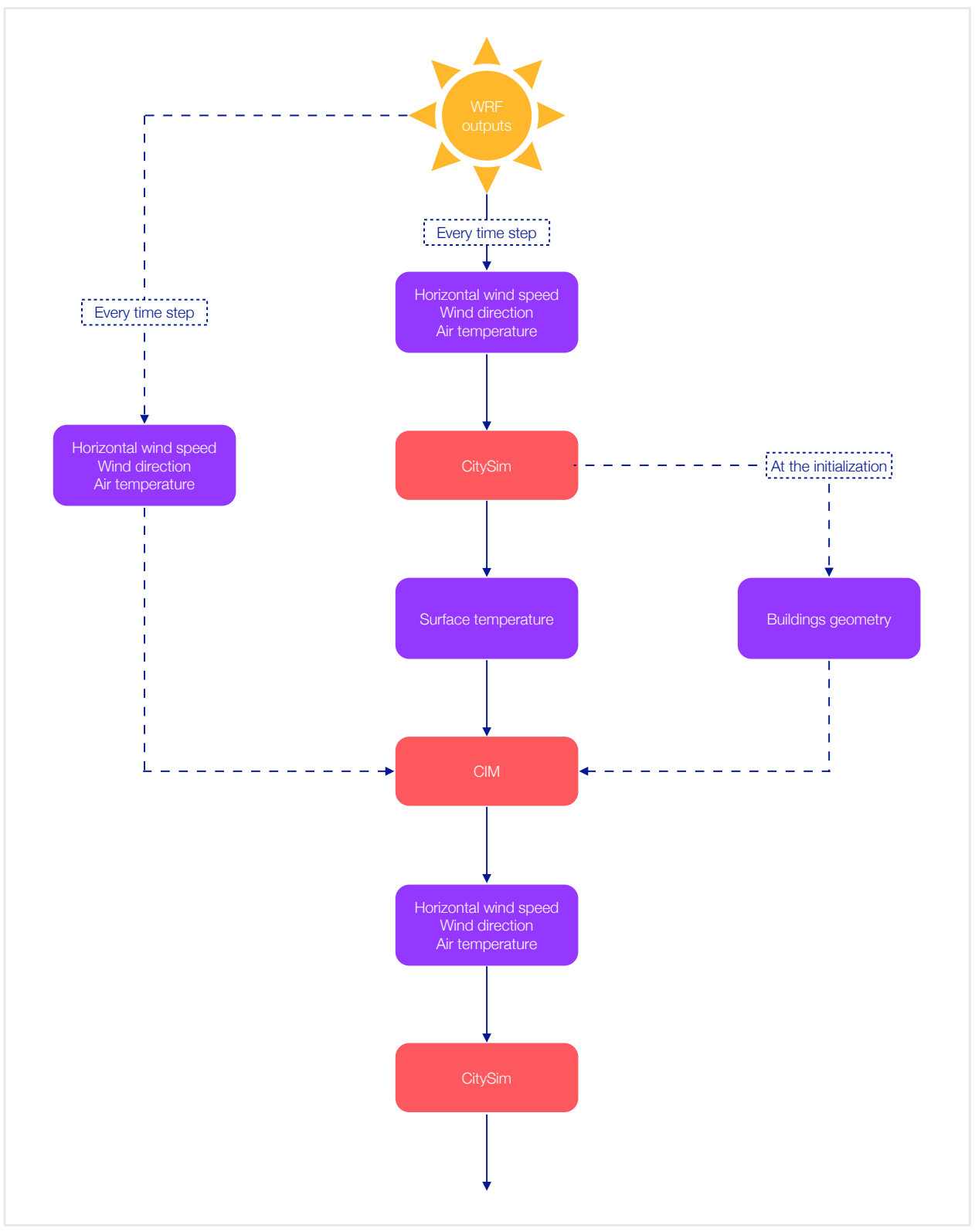

Fig. 5. Flowchart describing the coupling strategy CIM-CitySim adapted from Mauree et al. (2017) 
This is a pre-print of manuscript submitted for peer-review at Urban Climate

\section{STUDY CASE}

\subsection{MOdel SET UP}

During the heatwave of 2003, the mean temperatures of the months of June, July and August in Switzerland were 4.0 to $5.5^{\circ} \mathrm{C}$ higher than the mean summer temperature between 1864 and 2003 (Neu et al. 2005). To analyze the impact of the heat wave in this particular period, the experiments are carried out over the city of Lausanne, Switzerland, between the 14 July and 14 August 2003.

The WRF model is run over four domains with a respective resolution of $45 \mathrm{~km}, 15 \mathrm{~km}, 3 \mathrm{~km}$ and $1 \mathrm{~km}$ centered over the coordinates $46.5 \mathrm{~N}$ and $6.6 \mathrm{E}$ and a time step of $270 \mathrm{~s}$ for the coarser domain (Fig. 6).

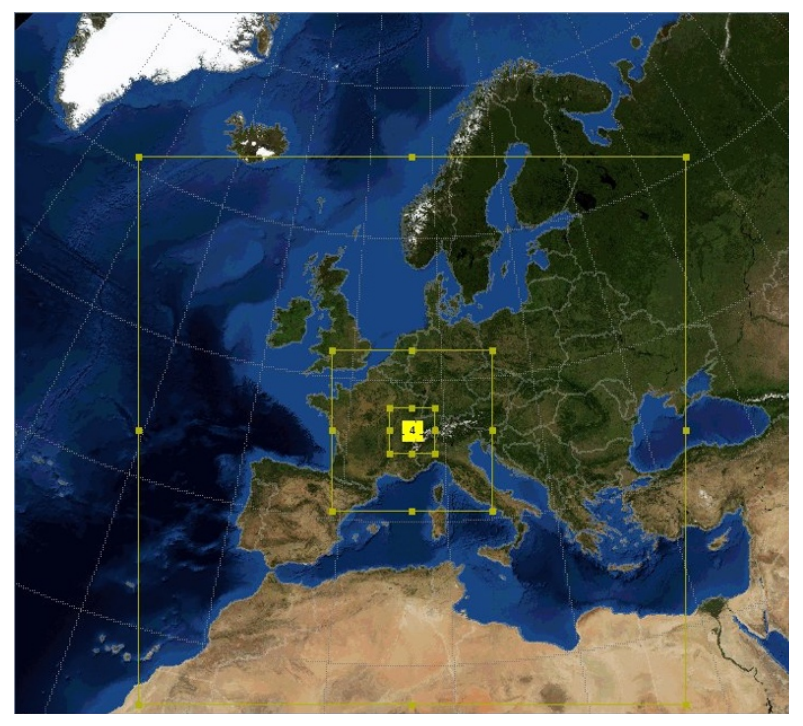

Fig. 6. Domains used for the WRF simulation

To address the impact of the future densification of urban areas in Switzerland, a focus is made on the dynamic region of the Lemanic arc and in particular the Lausanne-Geneva axis (Fig. 7). These two cities are respectively the $2^{\text {nd }}$ and the $4^{\text {th }}$ most populated cities of Switzerland. They 
This is a pre-print of manuscript submitted for peer-review at Urban Climate

are located in a temperate oceanic climate region according to the Köppen climate classification.

The city of Lausanne is built on a steep land composed by many hills that leads to a cramped urban development and the scarcity of large roads while Geneva is constrained by the lake on one side and by the French border on the other.

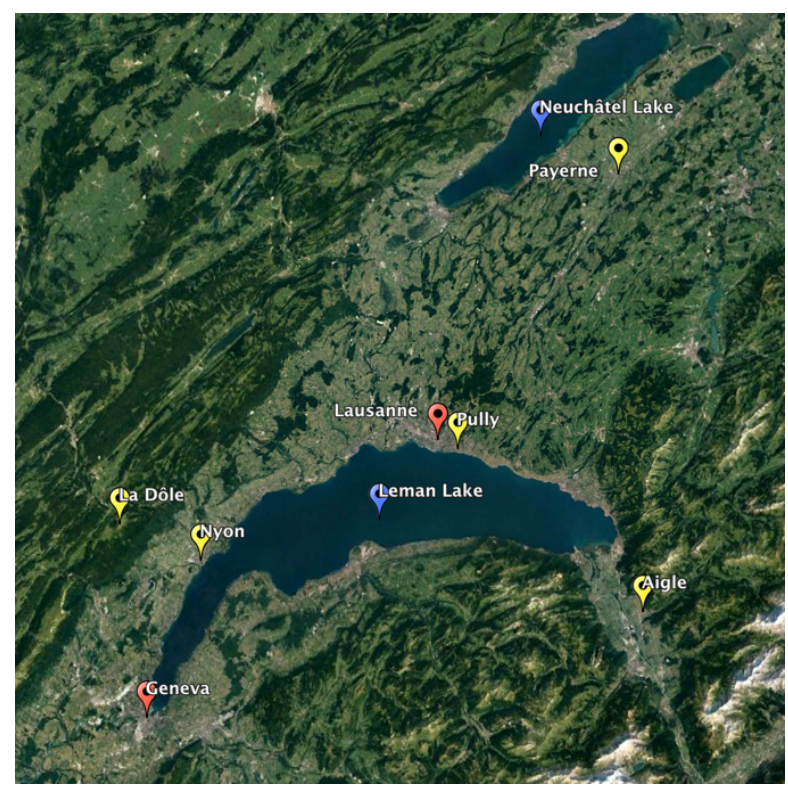

Fig. 7. Satellite image of the study domain

To highlight the impact of the urban climate on the building energy demand, the EPFL campus is simulated in CitySim with the WRF output data. It is located in Ecublens (46.52N,6.57E) and the CIM-CitySim system has been validated over the EPFL campus for the year 2015 (Mauree et al., 2015, 2017).

\subsection{SCENARIOS}

A special focus is placed on the densification of the cities planned by the Swiss Energy Strategy 2050. Indeed, Switzerland voted the territorial planning law's revision (LAT) of the 15th of June 2012 on the 1st of May 2014 to affirm its will to fight against the urban sprawl and to promote the urbanization development into the built environment. By this law, the Confederation wants 
This is a pre-print of manuscript submitted for peer-review at Urban Climate

to protect the agricultural lands, reduce the ecological impact of traffic network and boost the economic development of Swiss cities. Practically, this means an improvement of urban facilities and urban quality environment, a diminution of building lands, as well as the densification of urban areas by renovations, buildings extensions or new buildings constructions.

In order to analyze the effect of the urban densification on the urban climate and the impact of albedo and vegetation as several UHI mitigation strategies (Table 1), four scenarios is defined:

- Scenario 1: To highlight the UHI phenomenon, Lausanne is simulated with MODIS landuses, the three urban categories included.

- Scenario 2: To simulate the effect of the Swiss urban densification policy on the urban climate, the low density residential categories (class 31) are reclassified in high density (class 32) and hence taking the urban characteristics of the original high density category.

- Scenario 3 To analyze the impact of the greenings on the urban climate, Scenario 2 is modified to increase the greenings ratio of surfaces from $5 \%$ to $50 \%$.

- Scenario 4: To analyze the impact of the albedo on the urban climate, the albedo of walls and roofs are switched from respectively 0.20 and 0.1 to 0.8 . The simulation is done with the urban densification land use to take into account the future urbanization.

\begin{tabular}{c|cccc} 
& Scenario 1 & Scenario 2 & Scenario 3 & Scenario 4 \\
\hline $\begin{array}{c}\text { Mean urban } \\
\text { fraction }\end{array}$ & 0.37 & 0.69 & 0.69 & 0.69 \\
$\begin{array}{c}\text { Albedo of } \\
\text { roofs }\end{array}$ & 0.10 & 0.10 & 0.10 & 0.80 \\
$\begin{array}{c}\text { Albedo of } \\
\text { walls }\end{array}$ & 0.20 & 0.20 & 0.20 & 0.80 \\
$\begin{array}{c}\text { Greenings } \\
\text { ratio }\end{array}$ & 0.05 & 0.05 & 0.5 & 0.05
\end{tabular}

Table 1. Urban parameters of the scenarios 
This is a pre-print of manuscript submitted for peer-review at Urban Climate

The impact of the four scenarios are analyzed to understand the dynamics created by the presence of urban areas on the urban heat island phenomena and also on the local meteorology. Additionally, the air temperature at $2 \mathrm{~m}$ and the wind speed are extracted from the output meteorological data to assess the cooling energy consumption.

\section{RESULTS AND DISCUSSIONS}

\subsection{CLUSTERING}

The $k$-means clustering method was used to distribute the urban area in the three urban land use categories. We observe in the Fig. 8 that the urban morphology conform with the classic pattern of Swiss cities : cities are condensed in the lake side, city centers are denser than the surrounding and the commercial/industrial area are located in the city centers and in surrounding.

To be used by WRF, the map has been resampled from the resolution $200 \mathrm{~m}$ to $1 \mathrm{~km}$ by the nearest neighbor method (Fig. 8). Urban classes are discrete variables and this resampling method enables to manage this data without assigning a value which doesn't match with the urban classification. One of the drawbacks of the resampling is that some isolated urban areas have been transformed in rural area and it will thus not be considered as urban in the WRF simulation. Moreover, by the extension of the pixels size, some commercial/residential area are bigger than the reality and some rural areas are considered as urban area. This last case explain why some weather station located in rural area has been simulated as urban area in the control experiment (chapter 4.1).

Despite these approximations, this method is fast and repeatable for the study of urban area at the country scale. It enables the application of the densification scenario in a low processing time 
This is a pre-print of manuscript submitted for peer-review at Urban Climate

and we obtained a land use map typical of the urban distribution in Switzerland, usable by WRF for the simulation the urban climate in the Leman Lake area (Fig. 9).
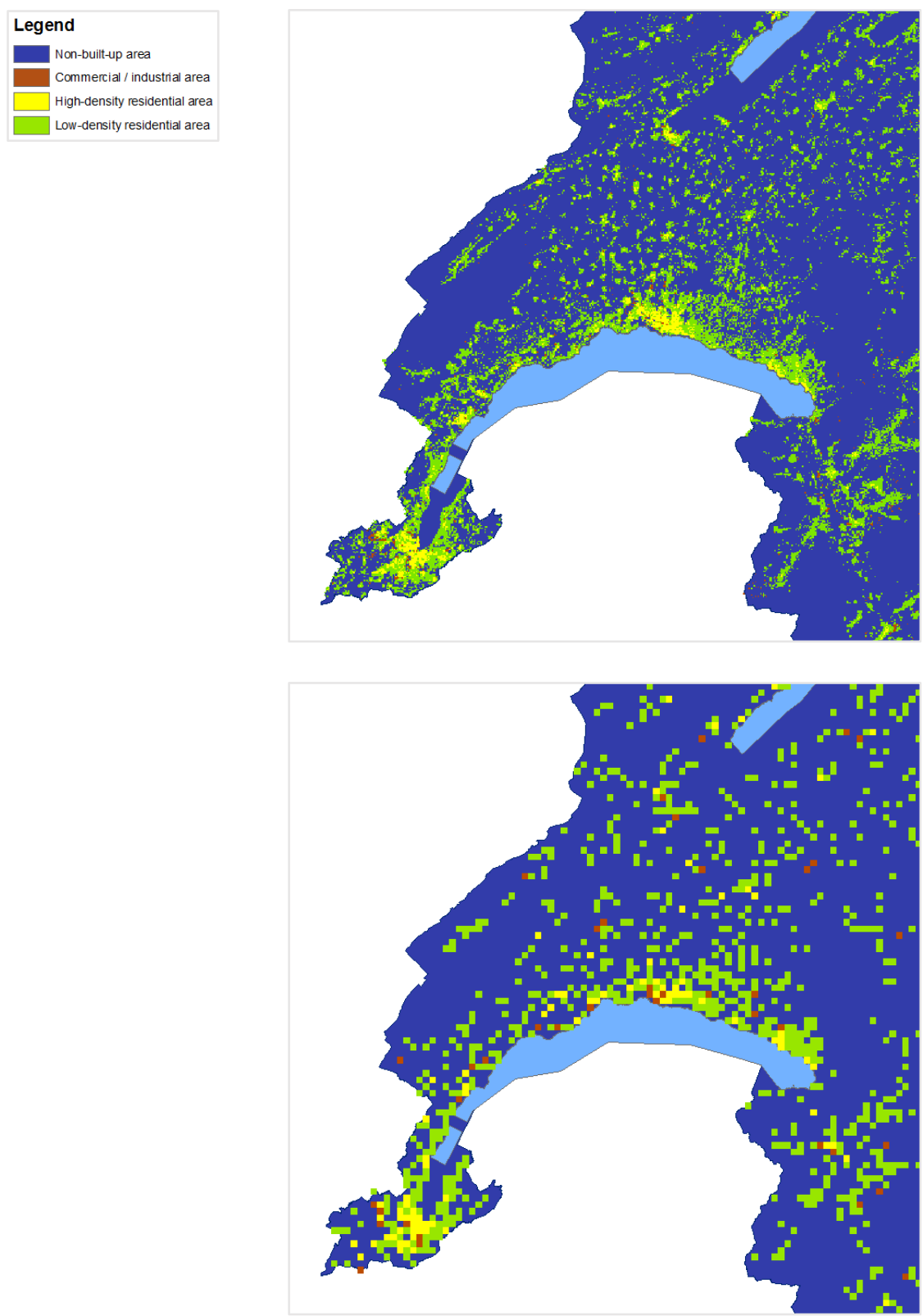

Fig. 8. Map of the classification of Swiss urban areas (sampling resolution $200 \mathrm{~m}$ - left and $1 \mathrm{~km}$-right) with in blue the rural area, in brown the commercial / industrial area, in yellow the high-density residential area and in green the low-density residential area 


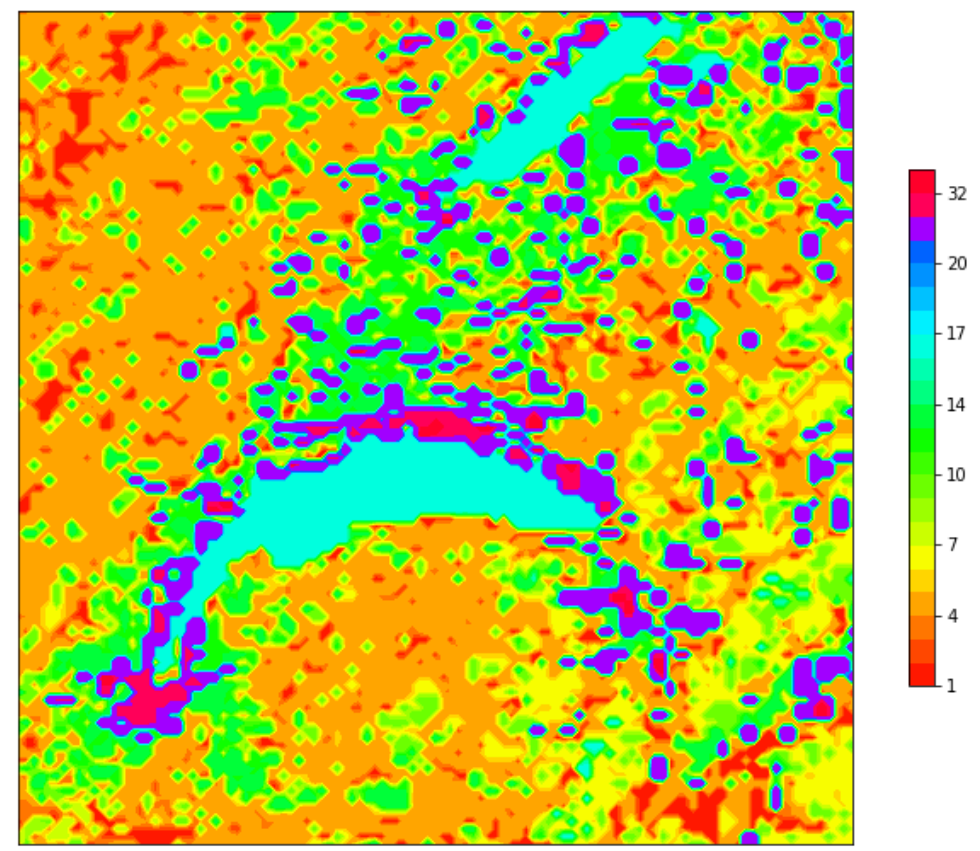

Fig. 9. Map of landuses used in WRF with created urban landuse and non-urban landuse from MODIS. Please refer to Channan (2014) for the MODIS classification indices.

\subsection{CONTROL EXPERIMENT}

For the purpose of this study, it was not possible to compare measured and simulated results in the urban areas because all the weather station are located outside the cities. However, some rural areas containing a weather station are located close to an urban area and they have been simulated as urban due to the $1 \mathrm{~km}$ clustering. These results have been compared in six different sites :

- Geneva : simulated as urban area in WRF, weather station located in the airport of Geneva.

- Nyon : simulated as urban area in WRF, weather station located in a steep rural area.

- Pully : simulated as urban area in WRF, weather station located in a steep rural area and near to a forest. 
This is a pre-print of manuscript submitted for peer-review at Urban Climate

- Aigle : simulated as rural area in WRF, weather station located in a rural area at the bottom of a valley.

- La Dôle : simulated as rural area in WRF, weather station located at the top of a mountain.

- Payerne : simulated as rural area in WRF, weather station located in a rural area, without obstacles.

The measured and simulated air temperature at $2 \mathrm{~m}$ and the wind speed and direction at $10 \mathrm{~m}$ are compared in the Fig. 10, 11 and 12. In Geneva, Nyon and Pully, the air temperature at $2 \mathrm{~m}$ simulated are lower than the measured data during the days and higher during the nights (Fig. 10). As mentioned previously, since the simulated areas are urbanized, it can be expected that the night air temperature are higher (Oke, 1982; Santamouris et al., 2001b). The building materials stock the heat during the day and restore it during the night. This highlights that interaction between the air and the building materials is well simulated by the BEP-BEM module of WRF and are consistent with previous findings (Salamanca et al., 2011). In the rural area, the morphology of the field significantly impacts the accuracy of the model. From the simulation of Aigle, it can be noted that the maximum temperature looks coherent with the measurement but during the night the temperatures do not fall by the same extent as in the observations (by up $\left.7^{\circ} \mathrm{C}\right)$ (Fig. 10). One of the reasons for this might be the lower wind speeds. as the model tend to perform imperfectly in complex and mountainous regions (Jiménez and Dudhia, 2012). Similarly, the mountainous region of La Dôle, makes the comparison is difficult. The results from the simulation shows, however, a better correspondence with the observations. In particular, the dynamics of the daily cycle are properly reproduced including the maxima and minima (except for the last days of August). In Payerne, a considerably better correspondence between measured and simulated data is obtained even if the simulated temperature are lower during the days (by approximatively $1^{\circ} \mathrm{C}$ to $5^{\circ} \mathrm{C}$ ). These results reflects studies (Jiménez and Dudhia, 2012) that 
This is a pre-print of manuscript submitted for peer-review at Urban Climate

suggested that WRF simulates temperatures for non-complex areas than areas located near to obstacles like mountains which can create strong turbulences and complex airflow.

. All the simulated wind speed are higher than the measured except in La Dôle (Fig. 11). At the top of the mountain the wind accelerate and the wind speed increase. Moreover, the simulated wind speeds of the simplest landuse area (Payerne) have the best correlation. These confirm that WRF poorly manage mountain area during its calculations and performs better when simulating non-complex land use. It can also be highlighted that the wind speeds obtained from WRF are diagnostic variables and hence they do not account for the low wind speed in the urban areas. This is clearly reflected in the comparison with the observations where generally higher wind speed are simulated. It can be noted from Fig. 12 that when CIM is used, there is a much better correspondence (decrease in bias of 0.68 ) with the observed data and are coherent with previous findings (Mauree et al., 2017).

These findings are also similar for the wind speed (Appendix C). The results for the comparison with the Pully station can be further explained by the forest in the North-North East and the slope between the weather station and the lake in the South. We observe in the Appendix B that the wind only comes from these two directions. The wind is blocked by these two obstacles and the wind speed measured by the weather station is very low. In our case, the rural area are simulated with "flat" landuse, without obstacles or roughness information which can explain these high wind speed compared to the reality.

The different wind roses of the Appendix B show that there is no coherence between measured and simulated wind direction. Note that all the majority of urban areas wind directions are 
This is a pre-print of manuscript submitted for peer-review at Urban Climate

oriented N-E/S-W which is one of the two streets orientations, parametrized in WRF. The later creates a street canyon which channels the wind and is then translated in the model.

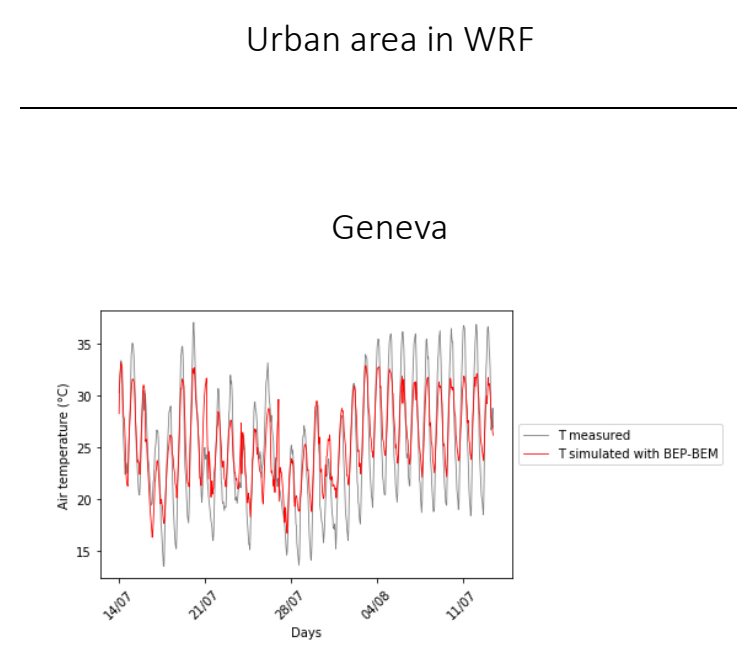

Nyon

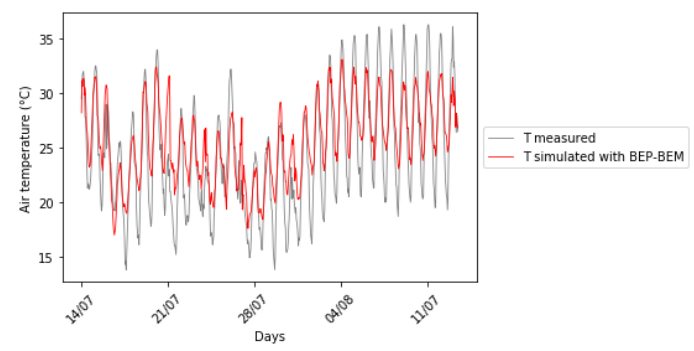

Pully (Lausanne)

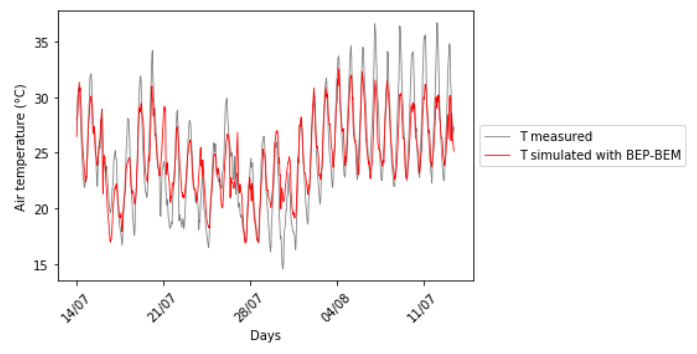

\section{Rural area in WRF}

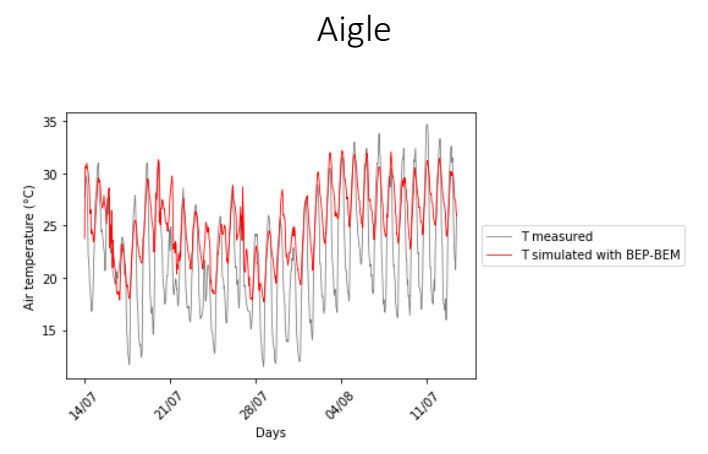

La Dôle

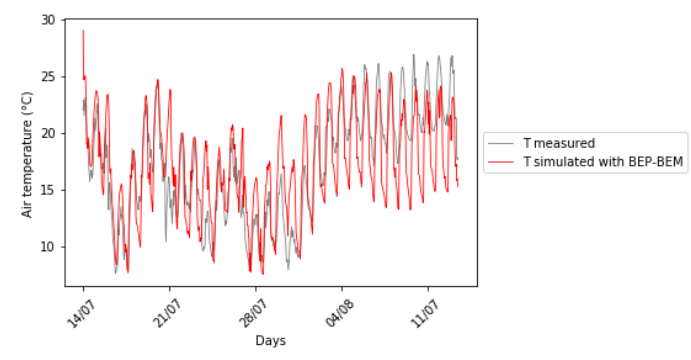

Payerne

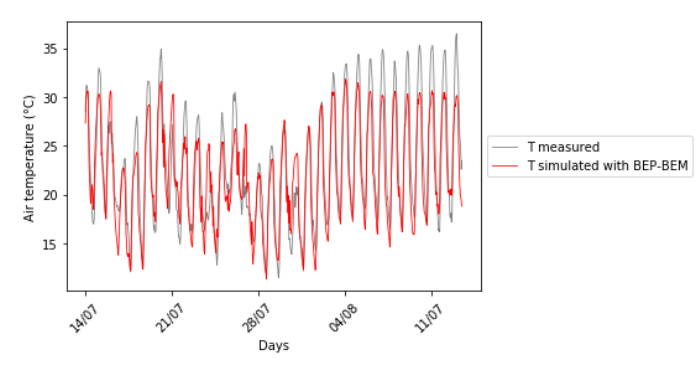

Fig. 10. Comparison of measured and simulated air temperature at $2 \mathrm{~m}$ for the summer 2003 in six different Swiss sites with in grey the temperatures measured by the weather station and in red the temperatures simulated in WRF 
This is a pre-print of manuscript submitted for peer-review at Urban Climate

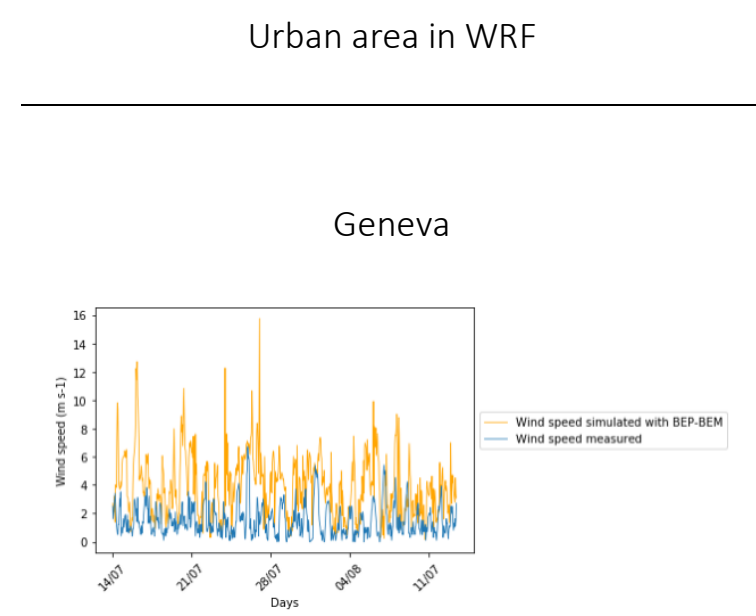

Rural area in WRF

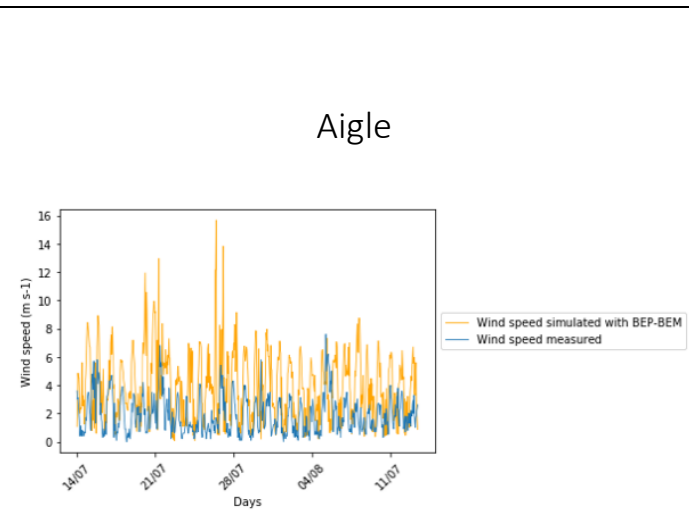

Nyon

La Dôle
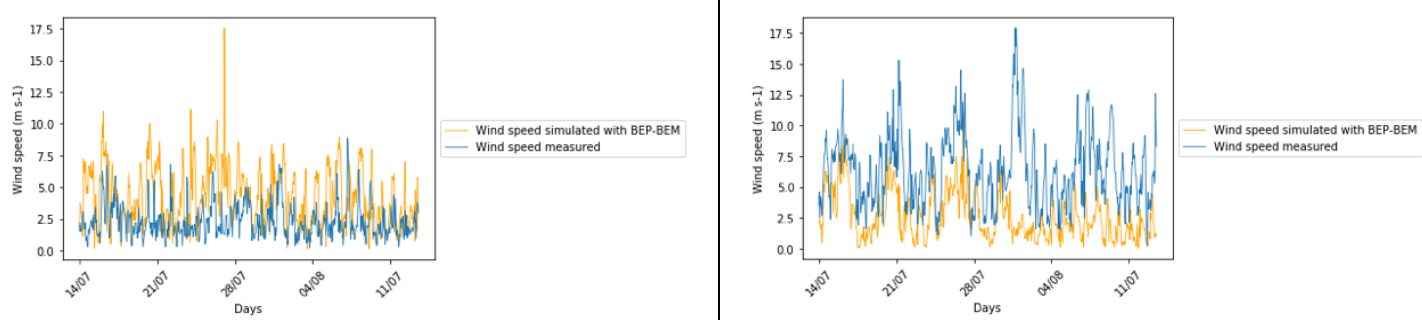

Pully (Lausanne)

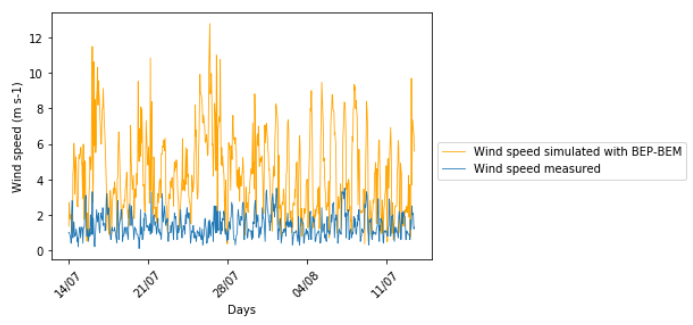

Payerne

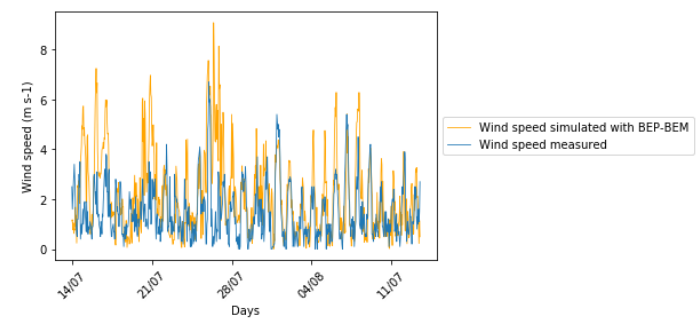

Fig. 11. Comparison of measured and simulated wind speed at $10 \mathrm{~m}$ for the summer 2003 in six different Swiss sites with in blue the temperatures measured by the weather station and in yellow the temperatures simulated in WRF. 


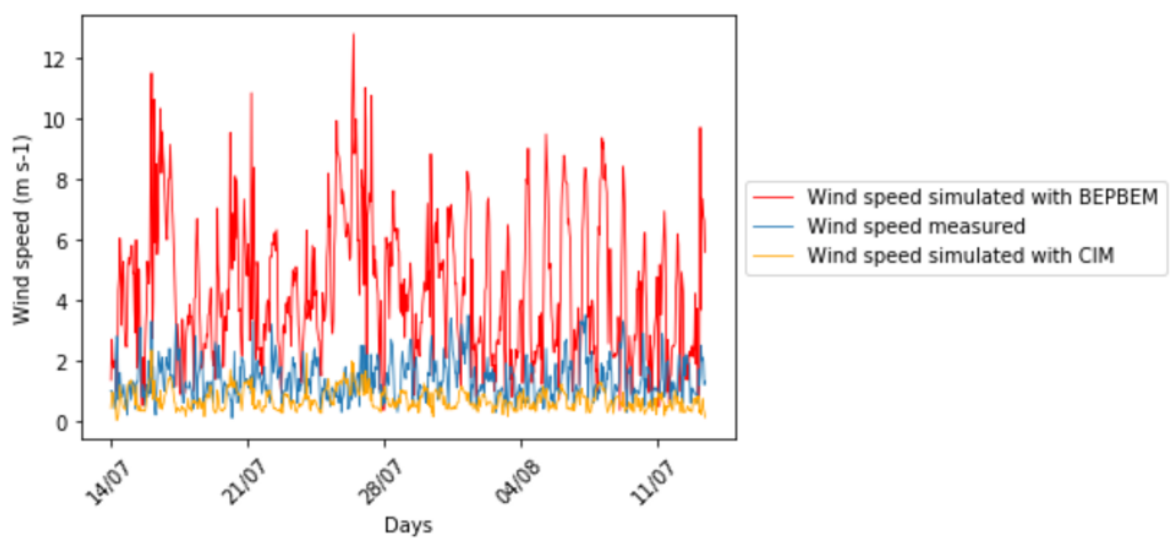

Fig. 12. Comparison of measured (at Pully station) and simulated wind speed at $10 \mathrm{~m}$ with outputs from WRF and from CIM for the summer 2003.

The Fig. 13 presents the monthly mean air temperature at $2 \mathrm{~m}$ of the BEP-BEM simulation during the hottest period of the day at $2 \mathrm{pm}$ ) and the coolest of the night (at $5 \mathrm{am}$ ). In the urban area, the temperature reaches on average a maximum of $30^{\circ} \mathrm{Cduring}$ the day time. The high temperature of Geneva create a heat plume which affects all the surrounding rural area. This phenomenon is also observable between the Leman Lake and the Neuchâtel Lake where Lausanne and the cities scattered in the valley create a heat corridor. The presence of multiple cities around the lake lead to the creation of the urban heat archipelago as described by Buyantuyev and Wu (2010). At the night time, the cities composed by impervious surface with high heat capacity, restore the heat accumulated during the day which create an air temperature difference between urban and rural area from $2^{\circ} \mathrm{C}$ to $4^{\circ} \mathrm{C}$. These observations highlight the extent of the urban heat island phenomena in the Lemanic region.

Moreover, we observe that the Leman lake is warmer than the hottest cities by $2^{\circ} \mathrm{C}$ at night. This phenomenon is due to its high heat capacity but maybe also to the presence of the warm urban area around it and the corresponding land breeze over the lake. 

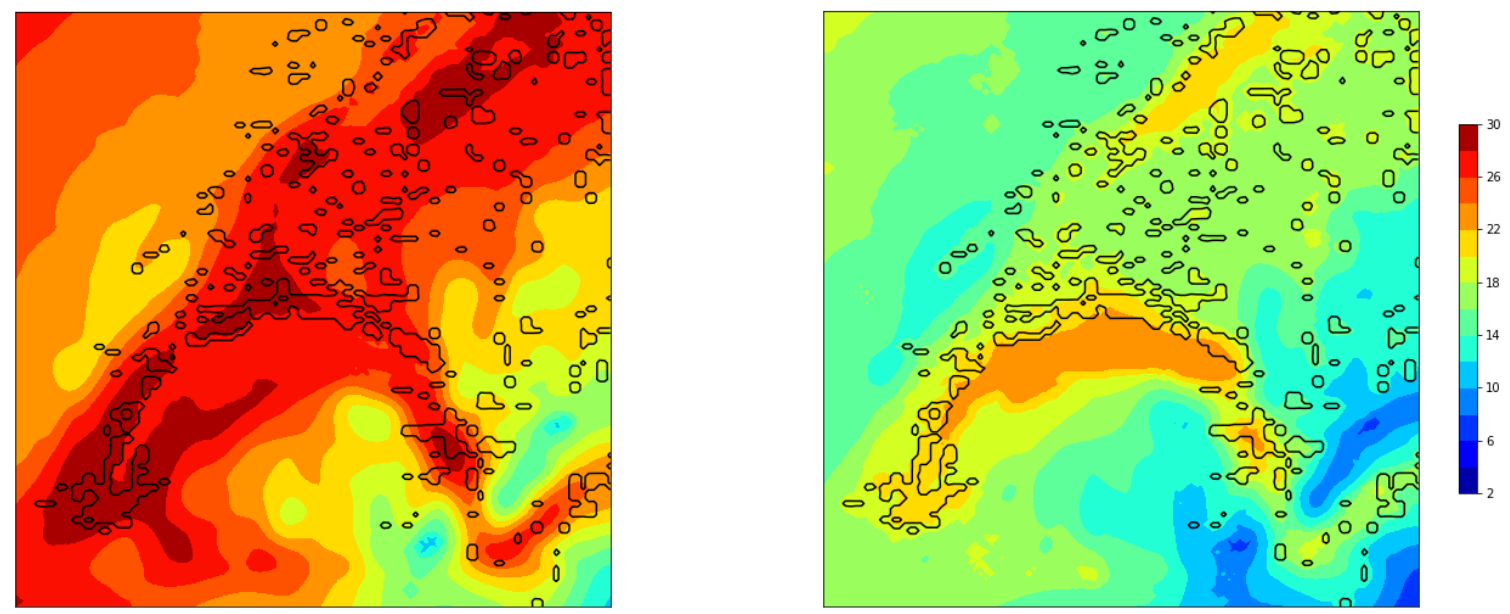

Fig. 13. Monthly mean air temperature at $2 \mathrm{~m}$ for the scenario 1 at $2 \mathrm{pm}$ and $5 \mathrm{am}\left({ }^{\circ} \mathrm{C}\right)$

\subsection{SCENARIOS}

Fig. 14 shows the new urban land use for the future dense scenarios. As mentioned previously, all land use class 31 were converted to land use class 32.

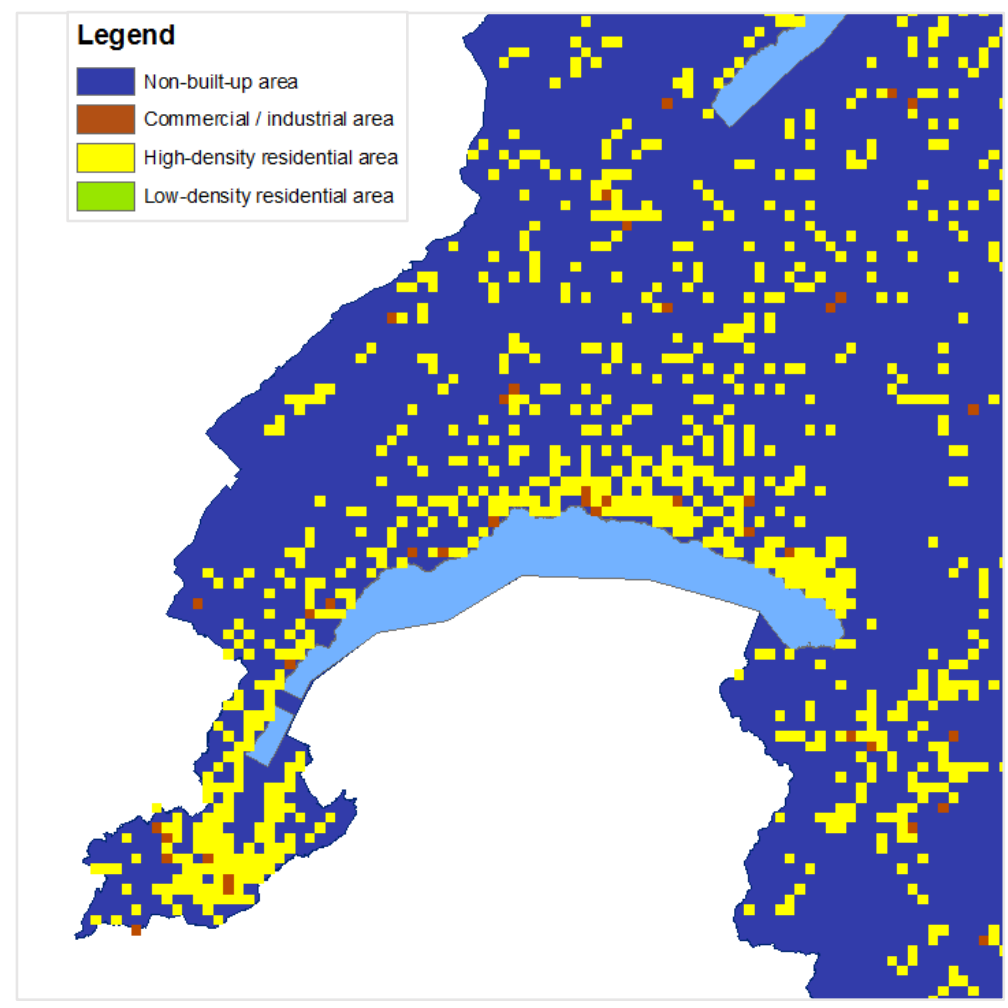

Fig. 14. Map of cluster of Swiss urban area Switzerland after densification (resolution : $1 \mathrm{~km}$ ) with in blue the rural area, in brown the commercial / industrial area, in yellow the high-density residential area and in green the low-density residential 
This is a pre-print of manuscript submitted for peer-review at Urban Climate

\subsubsection{Air temperature at 2M}

Fig. 15 shows the mean air temperature at $2 \mathrm{~m}$ of urban area, for the four scenarios during the last week of the study time. We have chosen this particular week because it was during this period that the heat wave was more intense.

During the heat peak, approximately at $2 \mathrm{pm}$, the increase of albedo reduces the air temperature by approximately $2^{\circ} \mathrm{C}$. With white walls and roofs, the buildings reflect more energy and stock less heating than greening surface or classic urban surface like concrete of tiles. We observe also that the densification leads to higher temperature values. This increases air temperature can be balanced by the use of greening surface, which draws near the base values.

But it is during the night that the impact of the urban densification is the most significant. In these areas,

During the night, the urban densification warms the urban climate by $0.8^{\circ} \mathrm{C}$ compare to the nondensify areas. This is due to the increasing of surfaces with high heating capacity which stock the heat during the day and restore it during the night. It is shown that the use of the vegetation and the increase of albedo was able to mitigate partially this effect. Moreover, these measures can reduce the air temperature in densified areas during the night such that they have similar temperatures to non-densified areas. 
This is a pre-print of manuscript submitted for peer-review at Urban Climate

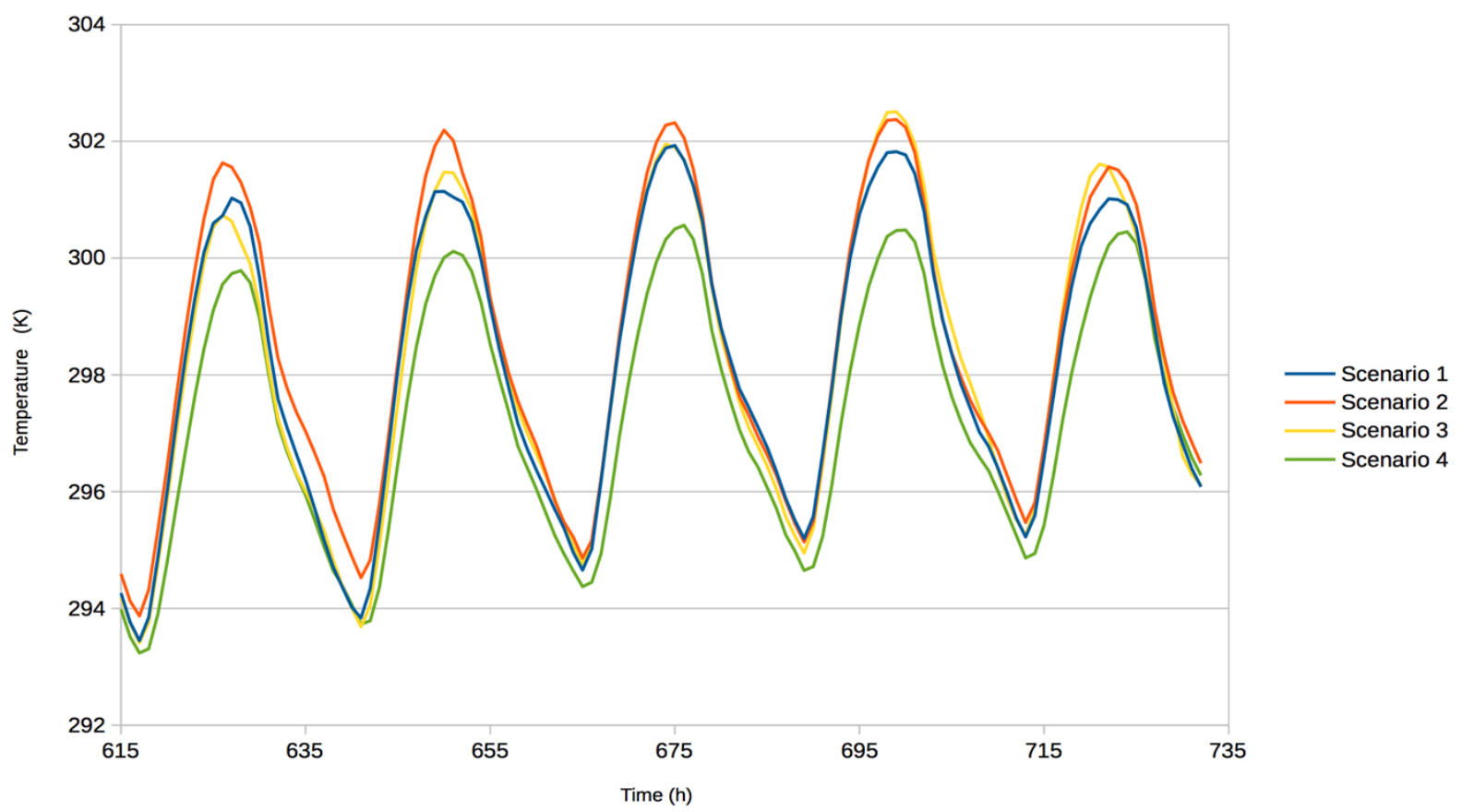

Fig. 15. Comparison of urban mean air temperature at $2 \mathrm{~m}$ of the 5 last days of the studied period between the four scenarios with in blue the temperature of the scenario 1, un orange the scenario 2, in yellow the scenario 3 and in green the scenario 4

The difference between the monthly mean air temperature at $2 \mathrm{~m}$ of the case study and the scenario of densification has been mapped during the day at $2 \mathrm{pm}$ and during the night at $5 \mathrm{am}$ (Fig.16). During the day, the difference of the values between the base case and the densification varies from $0.1^{\circ} \mathrm{C}$ to $0.5^{\circ} \mathrm{C}$. We can however observe heat plumes South of Geneva and North East of Lausanne which highlight the warming of rural area by the urban area. During the night, the densification causes an increase of the air temperature until $0.4^{\circ} \mathrm{C}$ in urban area. We observe the same effect of rural warming around the urban area observed during daytime. In Lausanne, the heat plumes moves toward the lake and slightly increases the air temperature above it. 

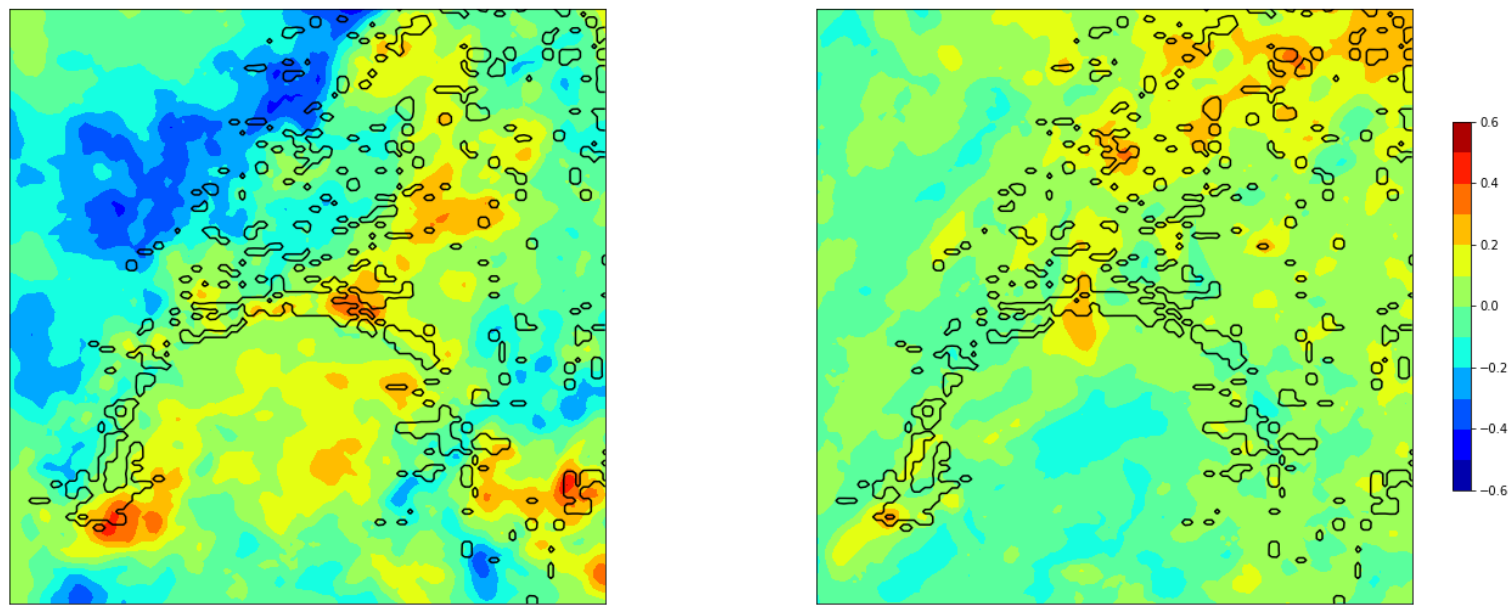

Fig. 16. Ditterence of monthly mean air temperature at $2 \mathrm{~m}$ between the scenarios 1 and 2 at $2 \mathrm{pm}$ and $5 \mathrm{am}\left({ }^{\circ} \mathrm{C}\right)$

Fig. 17 shows a decrease of $0.5^{\circ} \mathrm{C}$ of the temperature in the rural areas and by up to $0.8^{\circ} \mathrm{C}$ in city centers with the use of greenings in the dense scenario. The evapotranspiration of vegetation cools the air temperature inside the cities and also has a positive impact on the surrounding area as we can see the biggest air temperature difference in the area above Lausanne and around Neuchâtel. During the night, the impact of vegetation is less important than during heat peak. The air temperature in and around the Lake of Neuchâtel and in Geneva is cooler by $0.4^{\circ} \mathrm{C}$ and the urban heat island of Lausanne observed in Fig. 16 is reduced by $0.2^{\circ} \mathrm{C}$.

However, this low impact on air temperature could be due to the parametrization of the solution. We have chosen to increase the ratio of vegetation of the mesh without modify the building materials characteristics. The use of greening roofs and walls affects the heat capacity of the surface which could have an impact on the energy storage and on the urban climate. Additionally, when using vegetation in urban areas, the impact of the evapotranspiration is usually the main phenomenon responsible for cooling. The water content of the soil and availability for plants should hence be consistent with the measures proposed. This watering of plants and urban green spaces should be more clearly parameterized in WRF to enhance these phenomena. 

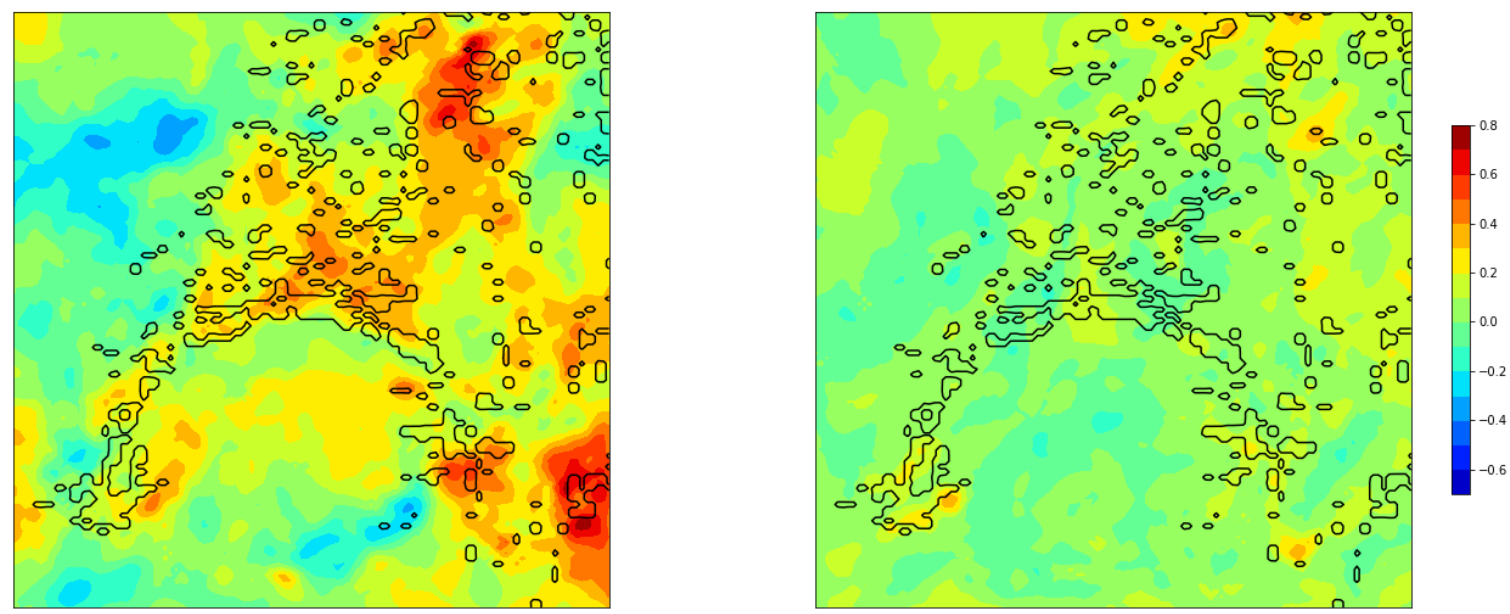

Fig. 17. Difference of monthly mean air temperature at $2 \mathrm{~m}$ between the scenarios 2 and 3 at $2 \mathrm{pm}$ and $5 a \mathrm{~m}\left({ }^{\circ} \mathrm{C}\right)$

Fig. 18 highlights the huge impact of the albedo on the urban climate and the rural surrounded area. The increase of albedo drops the air temperature in the city center of Lausanne by $2.8^{\circ} \mathrm{C}$ compare to the densification scenario. It also leads to decrease of the temperature in the rural area located between urban area caused by the diffusion of the heat from the cities by up to $1^{\circ} \mathrm{C}$. This propagation is also notable in the Leman Lake. The Lemanic arc, mainly composed by urban area, causes a rising of the air temperature above the lake by $1.5^{\circ} \mathrm{C}$. The use of light urban surface decreases the heating storage during the day by reflecting the energy which reduces these phenomena. During the night, this solution enable a reduction of the air temperature of all the urban zones and more specifically of the urban heat island of Geneva by $1.5^{\circ} \mathrm{C}$. Similar to the day, this figure highlights the warming of the Leman Lake by the restitution of the urban heat. 

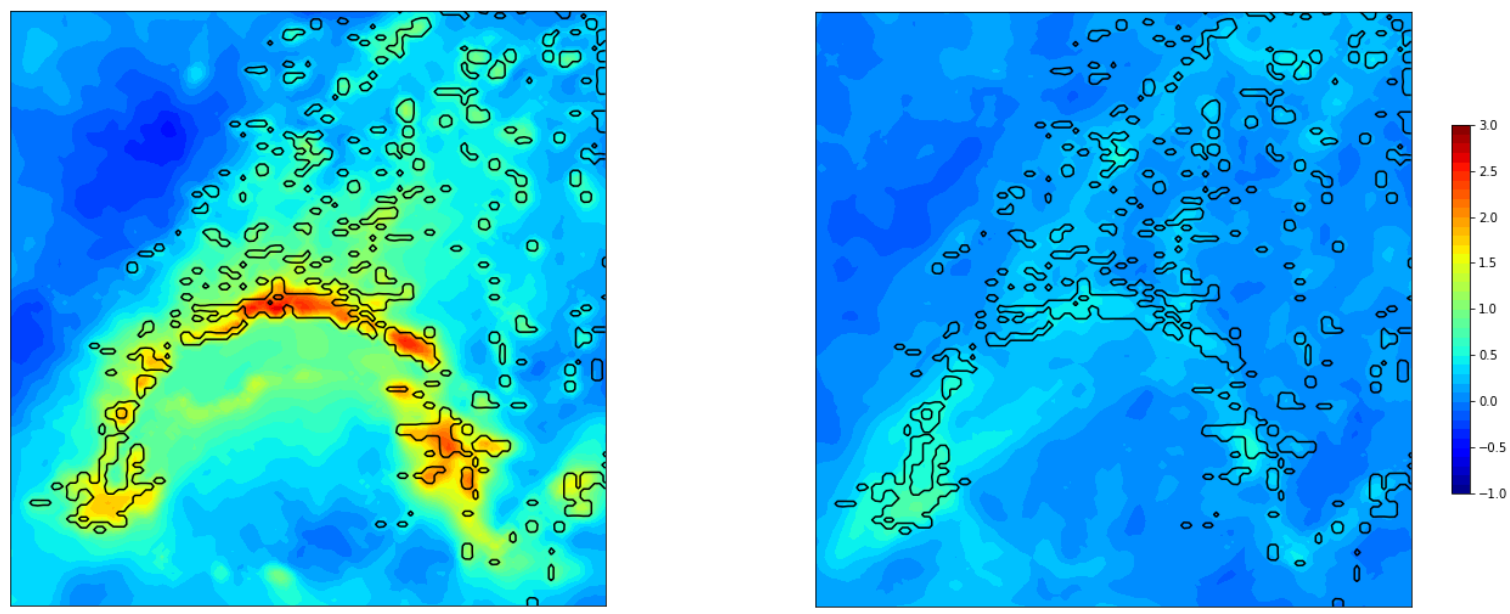

Fig. 18. Difference of monthly mean air temperature at $2 \mathrm{~m}$ between the scenarios 2 and 4 at $2 \mathrm{pm}$ and $5 \mathrm{am}\left({ }^{\circ} \mathrm{C}\right)$

\subsubsection{COOLING DEMAND}

These WRF output data are used as input in CitySim. To highlight the impact on the urban climate on the cooling demand, the urban characteristics have not been changed. Only the meteorological data of each scenarios are switched in this simulation. We observe in the Table 2 , the rise of the peak cooling demand of $12 \%$ for the scenario of densification. Moreover, the scenario 3 and 4 enhance a reduction of the peak cooling demand. In consequence, the future densification of urban area has a direct impact on cooling systems and the increase of albedo and the vegetation are both efficient mitigation strategies.

\begin{tabular}{c|cccc} 
& Scenario 1 & Scenario 2 & Scenario 3 & Scenario 4 \\
\hline $\begin{array}{c}\text { Peak cooling } \\
\text { demand }(\mathrm{kW})\end{array}$ & 2082 & 2336 & 2132 & 2192 \\
$\begin{array}{c}\text { \% w.r.t } \\
\text { Scenario 1 }\end{array}$ & - & $+12 \%$ & $+2 \%$ & $+5 \%$
\end{tabular}

Table 2. Comparison of the peak cooling demand (kW) of one part of the EPFL campus with meteorological input data from Meteonorm and fron WRF according to the four scenarios 
This is a pre-print of manuscript submitted for peer-review at Urban Climate

\section{Conclusion and Perspectives}

Heatwaves will become more frequent in the future due to climate change. Within the framework of Swiss Energy Strategy 2050 and the 2014 legislation on planning, Switzerland promotes the densification of urban areas. The combined effect of future land uses and of climate change on urban areas, especially on the intensity of urban heat island had not yet been addressed at the cantonal scale in Switzerland. The aim of this study was hence to assess the impact of the future urban planning scenarios on the urban climate in particular during a strong the heatwaves.

To integrate the urban characteristics in WRF according to its built density and its usage, the $k$ means clustering method has been used. With this method we obtained a good correspondence between the WRF input landuse and the real urban morphology with a sampling resolution of $200 \mathrm{~m}$. However, for the purpose of this study a $1 \mathrm{~km}$ horizontal resolution was used for the inner most domain. This aggregation caused some pixels values to be unrealistic at the frontier between rural and urban area. Moreover, this system doesn't consider the specificities of each cities because all the urban area belonging to one class have the same characteristics. The WUDAPT initiative (Mills et al., 2015) attempts to fill this gap by providing additional local climate zones categories that could be used as input for WRF. Nevertheless, the LCZ tweaks the urban landuse distribution but doesn't avoid the problem of the different urban specificities at the country scale. It is necessary to work in two times by using micro-scale model from meso-scale output data as boundary conditions.

With the actual urban planning, Geneva and Lausanne are warmer than surrounded rural area by $2^{\circ} \mathrm{C}$ during the day and from $2^{\circ} \mathrm{C}$ to $4^{\circ} \mathrm{C}$ during the night. These observations characterize the presence of the urban heat island in the Lemanic region and more particularly of the urban heat 
This is a pre-print of manuscript submitted for peer-review at Urban Climate

archipelago. The results of our study highlights that the future densification of the Lemanic urban area will slightly increase the intensity of already intense UHI- effect in the region. It will lead to the rise of the urban heat island by $0.4^{\circ} \mathrm{C}$ by night and by $0.6^{\circ} \mathrm{C}$ by day. The use of vegetation and the increase of albedo of walls and roofs have been investigated as mitigation strategies. The study demonstrates that the increase of the albedo leads to a drop of in the air temperature in urban area of $3^{\circ} \mathrm{C}$, against $0.8^{\circ} \mathrm{C}$ by using vegetation. In our simulation we have chosen to increase the greenings surfaces without changing the building material characteristics which can explain its low effect on the urban climate. A new parameterization taking into account characteristics of green roofs and vegetal walls needs to be investigated. However, the increase of albedo surface is already a good solution to mitigate the increase of the urban heat island due to the future urban densification planning. An assessment of the cooling demand was conducted using data obtained from WRF-BEP-BEM-CIM as boundary conditions for the energy software tool CitySim. It was demonstrated that the peak energy demand for the future scenarios will have a significant increase if no mitigation measures are taken. This will hence have direct consequences on the energy system sizing.

Studies need to be conducted on the impact of the urban areas on the Leman Lake. The increase in temperature $\left(2^{\circ} \mathrm{C}\right.$ higher than urban areas) or the lack of decrease in the temperature over the lake need to be better understood. Furthermore, the WRF model itself needs to be improved to better represent the meteorological phenomena in particularly complex regions.

\section{ACKNOWLEDGMENTS}

This research project is financially supported by the Swiss Innovation Agency Innosuisse and is part of the Swiss Competence Center for Energy Research SCCER FEEB\&D. 
This is a pre-print of manuscript submitted for peer-review at Urban Climate

\section{REFERENCES}

Akbari, H., Pomerantz, M., and Taha, H. (2001). Cool surfaces and shade trees to reduce energy use and improve air quality in urban areas. Sol. Energy 70, 295-310. doi:10.1016/S0038092X(00)00089-X.

Alcoforado, M. J., and Andrade, H. (2008). "Global Warming and the Urban Heat Island," in Urban Ecology, eds. J. M. Marzluff, E. Shulenberger, W. Endlicher, M. Alberti, G. Bradley, C. Ryan, et al. (Boston, MA: Springer US), 249-262. doi:10.1007/978-0-387-73412-5_14.

ARE, O. F. de l'Aménagement du T. LAT 1: Une mise en oeuvre conséquente du développement de l'urbanisation l'intérieur. https://www.are.admin.ch/are/fr/home/developpement-et-amenagement-du-territoire/droitde-I_amenagement-du-territoire/revision-de-la-loi-sur-lamenagement-du-territoire--lat-/lat-1-une-mise-en-oeuvre-consequente-du-developpement-de-lurban.html [Accessed August 20, 2018].

Arnfield, A. J. (2003). Two decades of urban climate research: a review of turbulence, exchanges of energy and water, and the urban heat island. Int. J. Climatol. 23, 1-26. doi:10.1002/joc.859. Assouline, D., Mohajeri, N., and Scartezzini, J.-L. (2018). Large-scale rooftop solar photovoltaic technical potential estimation using Random Forests. Appl. Energy 217, 189-211. doi:10.1016/j.apenergy.2018.02.118.

Boeing, G. (2017). OSMnx: New methods for acquiring, constructing, analyzing, and visualizing complex street networks. Comput. Environ. Urban Syst. 65, 126-139. doi:10.1016/j.compenvurbsys.2017.05.004.

Bruse, M., and Fleer, H. (1998). Simulating surface-plant-air interactions inside urban environments with a three dimensional numerical model. Environ. Model. Softw. 13, 373-384. doi:10.1016/S1364-8152(98)00042-5. 
This is a pre-print of manuscript submitted for peer-review at Urban Climate

Buyantuyev, A., \& Wu, J. (2010). Urban heat islands and landscape heterogeneity: Linking spatiotemporal variations in surface temperatures to land-cover and socioeconomic patterns. Landscape Ecology, 25(1), 17-33. DOI: 10.1007/s10980-009-9402-4

Channan, S., Collins, K., and Emanuel, W. R. (2014). Global mosaics of the standard MODIS land cover type data. Univ. Md. Pac. Northwest NatI. Lab. Coll. Park Md. USA 30.

Chen, F., Kusaka, H., Bornstein, R., Ching, J., Grimmond, C. S. B., Grossman-Clarke, S., et al. (2011). The integrated WRF/urban modelling system: development, evaluation, and applications to urban environmental problems. Int. J. Climatol. 31, 273-288. doi:10.1002/joc.2158.

Coccolo, S., Kämpf, J., Mauree, D., and Scartezzini, J.-L. (2018). Cooling potential of greening in the urban environment, a step further towards practice. Sustain. Cities Soc. 38, 543-559. doi:10.1016/j.scs.2018.01.019.

Crawley, D. B., Lawrie, L. K., Pedersen, C. O., and Winkelmann, F. C. (2000). Energy plus: energy simulation program. ASHRAE J. 42, 49-56.

Fallmann, J., Emeis, S., and Suppan, P. (2014). Modeling of the Urban Heat Island and its effect on Air Quality using WRF/WRF-Chem - Assessment of mitigation strategies for a Central European city. in Air Pollution Modeling and its Application XXIII Springer Proceedings in Complexity., eds.

D. Steyn and R. Mathur (Springer International Publishing), 373-377.

IPCC (2013). WORKING GROUP I CONTRIBUTION TO THE IPCC FIFTH ASSESSMENT REPORT CLIMATE CHANGE 2013: THE PHYSICAL SCIENCE BASIS. Geneva: Intergovernmental Panel on Climate Change.

Jiménez, P. A., and Dudhia, J. (2012). Improving the Representation of Resolved and Unresolved Topographic Effects on Surface Wind in the WRF Model. J. Appl. Meteorol. Climatol. 51, 300-316. doi:10.1175/JAMC-D-11-084.1.

Kikegawa, Y., Genchi, Y., Yoshikado, H., and Kondo, H. (2003). Development of a numerical simulation system toward comprehensive assessments of urban warming countermeasures 
This is a pre-print of manuscript submitted for peer-review at Urban Climate

including their impacts upon the urban buildings' energy-demands. Appl. Energy 76, 449-466. doi:10.1016/S0306-2619(03)00009-6.

Kondo, H., Genchi, Y., Kikegawa, Y., Ohashi, Y., Yoshikado, H., and Komiyama, H. (2005). Development of a Multi-Layer Urban Canopy Model for the Analysis of Energy Consumption in a Big City: Structure of the Urban Canopy Model and its Basic Performance. Bound.-Layer Meteorol. 116, 395-421. doi:10.1007/s10546-005-0905-5.

Krayenhoff, E. S., and Voogt, J. A. (2007). A microscale three-dimensional urban energy balance model for studying surface temperatures. Bound-Layer Meteorol. 123, 433-461. doi:10.1007/s10546-006-9153-6.

Martilli, A. (2007). Current research and future challenges in urban mesoscale modelling. Int. J. Climatol. 27, 1909-1918. doi:10.1002/joc.1620.

Mauree, D. (2014). Development of a multi-scale meteorological system to improve urban climate modeling.

Mauree, D., Blond, N., and Clappier, A. (2018). Multi-scale modeling of the urban meteorology: Integration of a new canopy model in the WRF model. Urban Clim. 26, 60-75. doi:10.1016/j.uclim.2018.08.002.

Mauree, D., Blond, N., Kohler, M., and Clappier, A. (2017a). On the Coherence in the Boundary Layer: Development of a Canopy Interface Model. Front. Earth Sci. 4. doi:10.3389/feart.2016.00109.

Mauree, D., Coccolo, S., Kaempf, J., and Scartezzini, J.-L. (2017b). Multi-scale modelling to evaluate building energy consumption at the neighbourhood scale. PLOS ONE 12, e0183437. doi:10.1371/journal.pone.0183437.

Mauree, D., Coccolo, S., Kaempf, J., and Scartezzini, J.-L. (2017c). Multi-scale modelling to evaluate building energy consumption at the neighbourhood scale. PLOS ONE 12, e0183437. doi:10.1371/journal.pone.0183437. 
This is a pre-print of manuscript submitted for peer-review at Urban Climate

Mauree, D., Coccolo, S., Kämpf, J., and Scartezzini, J.-L. (2016). Multi-scale modelling to assess human comfort in urban canyons. Expand. Boundaries - Syst. Think. Built Environ. - Proc. Sustain. Built Environ. SBE Reg. Conf. Zurich 2016. doi:10.3218/3774-6_15.

Mauree, D., Kämpf, J. H., and Scartezzini, J.-L. (2015a). Multi-scale modelling to improve climate data for building energy models. in Proceeding of the 14th International Conference of the International Building Performance Simulation Association, Hyderabad, India, December 6-9, 2015 14th International Conference of the International Building Performance Simulation Association, Hyderabad, India, December 6-9, 2015. Available at: http://infoscience.epfl.ch/record/214837 [Accessed February 16, 2018].

Mauree, D., Nadège, B., Clappier, A., Kämpf, J. H., and Scartezzini, J.-L. (2015b). Evaluation of building energy use: from the urban to the building scale. in Proceedings of the 9th International Conference on Urban Climate (Toulouse). Available at: http://infoscience.epfl.ch/record/211913 [Accessed October 20, 2015].

Morini, E., Touchaei, A. G., Castellani, B., Rossi, F., and Cotana, F. (2016). The Impact of Albedo Increase to Mitigate the Urban Heat Island in Terni (Italy) Using the WRF Model. Sustainability 8, 999. doi:10.3390/su8100999.

Nunez, M., and Oke, T. R. (1977). The Energy Balance of an Urban Canyon. J. Appl. Meteorol. 16, 11-19. doi:10.1175/1520-0450(1977)016<0011:TEBOAU>2.0.CO;2.

Oke, T. R. (1982). The energetic basis of the urban heat island. Q. J. R. Meteorol. Soc. 108, 1-24. doi:10.1002/qj.49710845502.

Perez, D. A framework to model and simulate the disaggregated energy flows supplying buildings in urban areas. 204.

Robinson, D. (2012). Computer Modelling for Sustainable Urban Design: Physical Principles, Methods and Applications. Routledge.

Salamanca, F., Krpo, A., Martilli, A., and Clappier, A. (2010). A new building energy model coupled 
This is a pre-print of manuscript submitted for peer-review at Urban Climate

with an urban canopy parameterization for urban climate simulations-part I. formulation, verification, and sensitivity analysis of the model. Theor. Appl. Climatol. 99, 331-344. doi:10.1007/s00704-009-0142-9.

Salamanca, F., Martilli, A., Tewari, M., and Chen, F. (2011). A study of the urban boundary layer using different urban parameterizations and high-resolution urban canopy parameters with WRF. J. Appl. Meteorol. Climatol. 50, 1107-1128.

Santamouris, M. (2013). Energy and Climate in the Urban Built Environment. Routledge.

Santamouris, M., Papanikolaou, N., Livada, I., Koronakis, I., Georgakis, C., Argiriou, A., et al. (2001a). On the impact of urban climate on the energy consumption of buildings. Sol. Energy 70, 201-216. doi:10.1016/\$0038-092X(00)00095-5.

Santamouris, M., Papanikolaou, N., Livada, I., Koronakis, I., Georgakis, C., Argiriou, A., et al. (2001b). On the impact of urban climate on the energy consumption of buildings. Sol. Energy 70, 201-216. doi:10.1016/S0038-092X(00)00095-5.

Stewart, I. D., Oke, T. R., Stewart, I. D., and Oke, T. R. (2012). Local Climate Zones for Urban Temperature Studies. Httpdxdoiorg101175BAMS--11-000191. doi:10.1175/BAMS-D-11-00019.1. Touchaei, A. G., and Akbari, H. (2015). Evaluation of the seasonal effect of increasing albedo on urban climate and energy consumption of buildings in Montreal. Urban Clim. 14, 278-289. doi:10.1016/j.uclim.2015.09.007.

Trusilova, K., Früh, B., Brienen, S., Walter, A., Masson, V., Pigeon, G., et al. (2013). Implementation of an Urban Parameterization Scheme into the Regional Climate Model COSMO-CLM. J. Appl. Meteorol. Climatol. 52, 2296-2311. doi:10.1175/JAMC-D-12-0209.1.

United Nations, D. of E. and S. A., Population Division (2017). World Population Prospects: The 2017 Revision, Key Findings and Advance Tables. Available at: https://esa.un.org/unpd/wpp/Publications/Files/WPP2017_KeyFindings.pdf.

Xu, X., González, J. E., Shen, S., Miao, S., and Dou, J. (2018). Impacts of urbanization and air 
This is a pre-print of manuscript submitted for peer-review at Urban Climate

pollution on building energy demands - Beijing case study. Appl. Energy 225, 98-109. doi:10.1016/j.apenergy.2018.04.120. 
APPENDIX A: URBAN PARAMETRIZATION FROM URBPARM.TBL

\begin{tabular}{|c|c|c|c|}
\hline CHARACTERISTICS & LOW DENSITY RESIDENTIAL & $\begin{array}{l}\text { HIGH DENSITY } \\
\text { RESIDENTIAL }\end{array}$ & COMMERCIAL/INDUSTRIAL \\
\hline $\begin{array}{c}\text { STREET } \\
\text { DIRECTIONS (DEG } \\
\text { FROM NORTH) }\end{array}$ & $\begin{array}{l}30.0 \\
120.0\end{array}$ & $\begin{array}{l}30.0 \\
120.0\end{array}$ & $\begin{array}{c}30.0 \\
120.0\end{array}$ \\
\hline $\begin{array}{l}\text { STREET WIDTH } \\
\text { (M) }\end{array}$ & 32 & 70 & 30 \\
\hline $\begin{array}{l}\text { BUILDING WIDTH } \\
\text { (M) }\end{array}$ & 327 & 702 & 296 \\
\hline \multicolumn{4}{|l|}{$\begin{array}{l}\text { BUILDING HEIGHT } \\
\text { DISTRIBUTION (\%) }\end{array}$} \\
\hline $5 \mathrm{M}$ & 0 & 0 & 15 \\
\hline $10 \mathrm{M}$ & 27 & 0 & 41 \\
\hline $15 \mathrm{M}$ & 41 & 10 & 31 \\
\hline $20 \mathrm{M}$ & 22 & 38 & 8 \\
\hline $25 \mathrm{M}$ & 6 & 43 & 5 \\
\hline $30 \mathrm{M}$ & 2 & 9 & 0 \\
\hline $40 \mathrm{M}$ & 2 & 0 & 0 \\
\hline \multicolumn{4}{|l|}{$\begin{array}{c}\text { THERMAL } \\
\text { CONDUCTIVITY } \\
\text { [ J M }\{-1\} \text { S }\{-1\} K\{- \\
1\}]\end{array}$} \\
\hline ROOFS & 0.91 & 0.97 & 0.84 \\
\hline WALLS & 0.91 & 0.97 & 0.84 \\
\hline ROADS & 0.40 & 0.40 & 0.40 \\
\hline \multicolumn{4}{|l|}{$\begin{array}{l}\text { HEAT CAPACITY } \\
\text { [ J M }\{-3\} \mathrm{K}\{-1\} \text { ] }\end{array}$} \\
\hline ROOFS & 1473706 & 1475442 & 1496853 \\
\hline WALLS & 1473706 & 1475442 & 1496853 \\
\hline ROADS & 1473706 & 1475442 & 1496853 \\
\hline ALBEDO & & & \\
\hline ROOFS & 0.10 & 0.10 & 0.10 \\
\hline WALLS & 0.20 & 0.20 & 0.20 \\
\hline ROADS & 0.05 & 0.05 & 0.05 \\
\hline VEGETATION (\%) & 5.0 & 5.0 & 5.0 \\
\hline
\end{tabular}


This is a pre-print of manuscript submitted for peer-review at Urban Climate

APPENDIX B: RMSE AND BIAS OF THE WIND SPEED BETWEEN MEASURED BY WEATHER STATION AND SIMULATED BY WRF

\begin{tabular}{|c|c|c|}
\hline Weather station & RMSE & BIAS \\
\hline Pully & 3.71 & 2.91 \\
AIGLE & 3.05 & 2.08 \\
GENEVA & 3.31 & 2.46 \\
LA DÔLE & 4.78 & 3.75 \\
NYON & 3.00 & 1.93 \\
PAYERNE & 1.64 & 0.70 \\
\hline
\end{tabular}




\section{APPENDIX C: WIND DIRECTION COMPARISON}

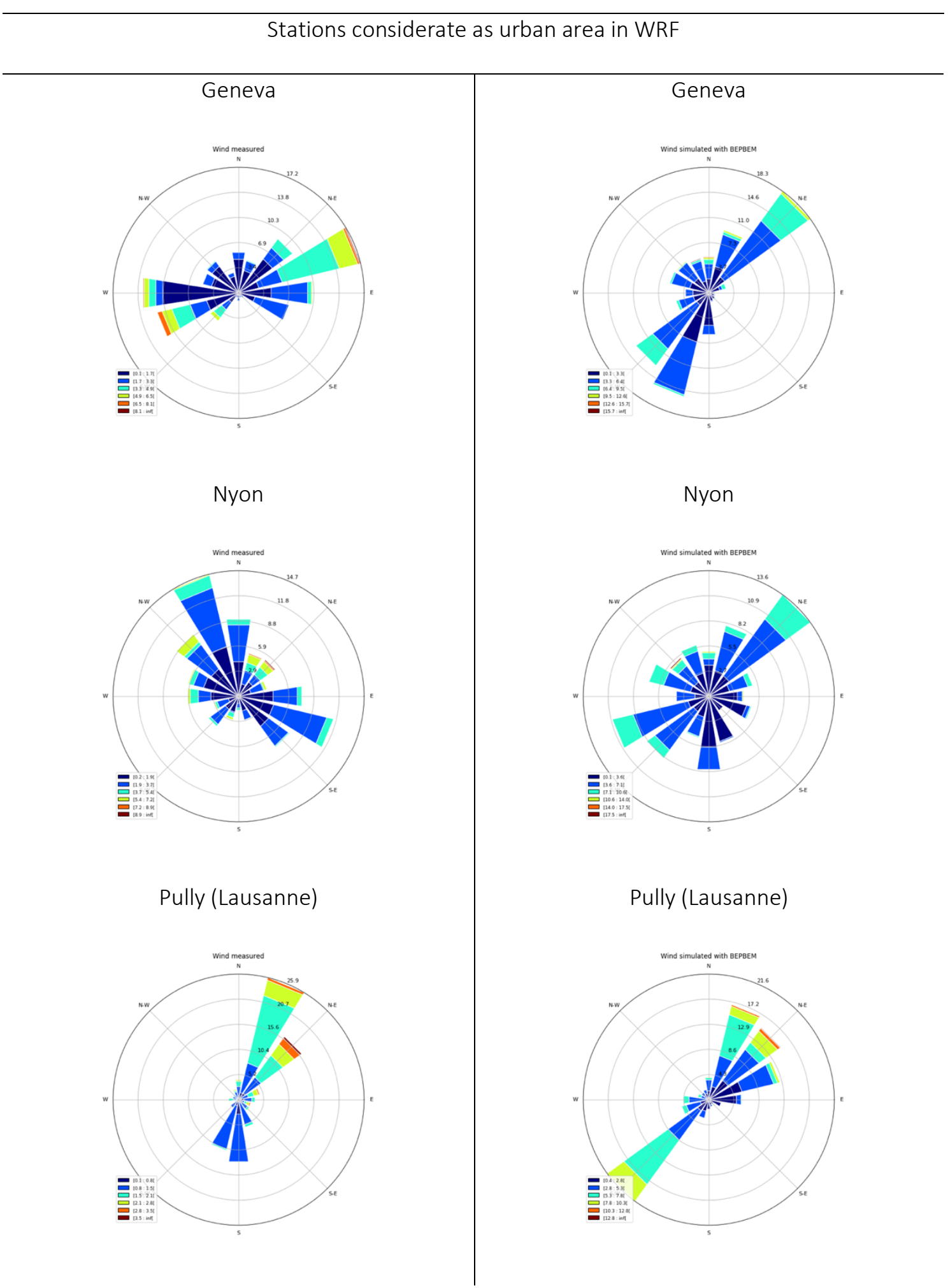


This is a pre-print of manuscript submitted for peer-review at Urban Climate

Measured data

Simulated data

Stations considerate as rural area in WRF

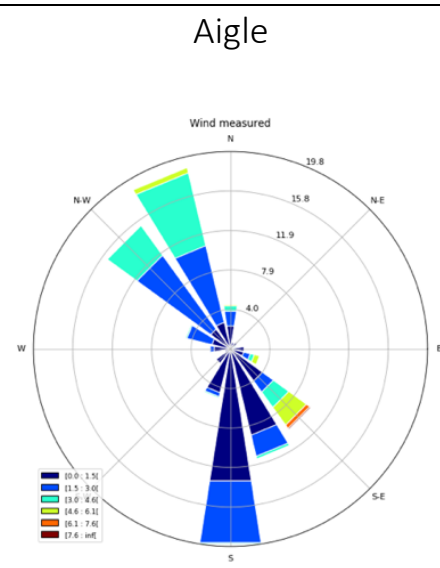

La Dôle

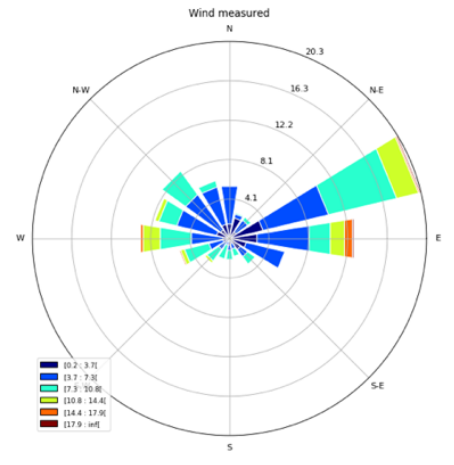

Payerne

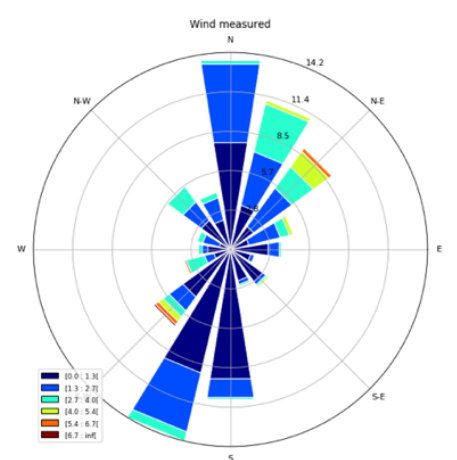

Aigle

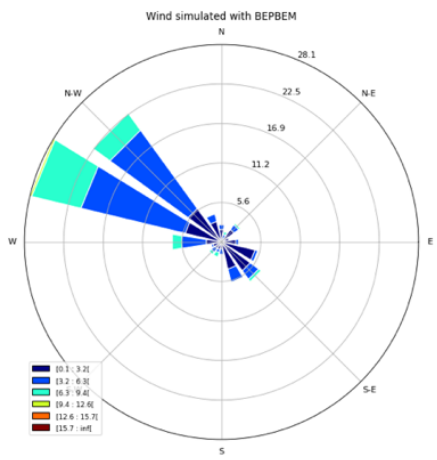

La Dôle

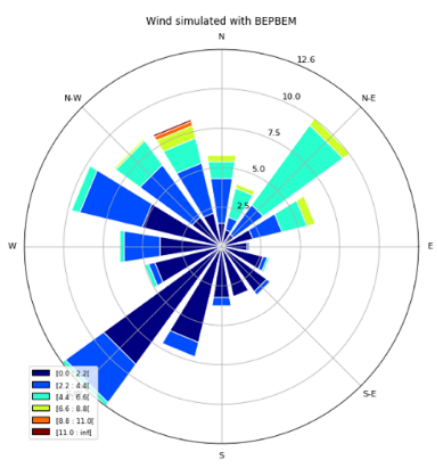

Payerne

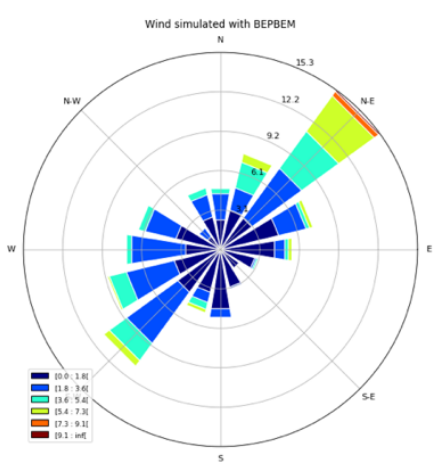

